\title{
GROUPNESS RACIAL E FLUTUAÇÓES ATITUDINAIS DE PARDOS ENTRE FRONTEIRAS SIMBÓLICAS E SOCIAIS
}

\section{Jerônimo Oliveira Muniz}

https://orcid.org/0000-0002-5697-9516

\section{Nathália Porto $(2)$}

https://orcid.org/0000-0002-8617-9499

\section{Mario Fuks}

https://orcid.org/0000-0003-2482-295X

(1) Universidade Federal de Minas Gerais (UFMG), Belo Horizonte - MG, Brasil. E-mail: jeronimo@ufmg.br

(2) IPSOS Brasil, São Paulo - SP, Brasil. E-mail: nathaliafporto@gmail.com

(3) Universidade Federal de Minas Gerais (UFMG), Belo Horizonte - MG, Brasil. E-mail: mariofuks@gmail.com

DOI: $10.1590 / 3410107 / 2019$

\section{Introdução}

Em 18 de março de 2016, cerca de 95 mil pessoas se uniram na Avenida Paulista para apoiar o governo de Dilma Rousseff. Destas, 58\% eram homens, $80 \%$ faziam parte da população economicamente ativa (PEA), 62\% se autodeclararam brancas e 78\% tinham ensino superior. $\mathrm{Na}$ semana anterior, $500 \mathrm{mil}$ haviam se unido na mesma região, para protestar contra o Governo, das quais 57\% eram do sexo masculino, $88 \%$ faziam parte da PEA, 77\% declararam-se da cor branca, e mesma proporção tinha ensino superior. Estes dois grupos não se diferenciaram, portanto, pelos seus atributos sociodemográficos, mas sim pelo seu apoio ou reprovação ao governo de Dilma Rousseff. ${ }^{1}$ Os integrantes dessas manifestaçóes não se juntaram em um espaço público por fatores como sexo, raça ou

Artigo recebido em: 19/01/2018

Aprovado em: 30/04/2019 escolaridade, mas sim por partilharem percepçóes, atitudes e sentimentos comuns em relação ao Governo. Este exemplo, no qual um grupo de pessoas possui uma identidade social compartilhada, um sentimento de grupo, ilustra o conceito de groupness (Brubaker, 2002, 2009; Campbell, 1958).

Agrupamentos estes, cujos membros possuem um entendimento comum dos rituais e das normas sociais, e nos quais há um sentimento compartilhado sobre o propósito e a habilidade de seus membros em manter tal coesão, são grupos em que há o que se define como groupness, que dá a qualidade de grupo - minimamente coeso e solidário - a um agrupamento qualquer de indivíduos. Brubaker e Cooper (2000, p. 7 apud Lamont et al., 2016, p. 23), por exemplo, definem groupness como "um sentimento de pertença a um grupo solidário, distinto e delimitado" e com "uma uniformidade fundamental entre os membros do grupo ou categoria" (ver também Brubaker, 2002, 2009). 
Investigar o que origina, mantém e dá significado a agrupamentos sociais é importante para entender como as pessoas processam informação e formam impressôes (por exemplo: preconceitos, estigmas e avaliaçóes depreciativas) sobre as pessoas categorizadas em tais grupos. Apesar da enorme diversidade humana, é a percepção de atitudes comuns que permite às pessoas agregarem indivíduos em vulgas unidades de sentido (estereótipos), permitido assim um processamento mais eficiente da complexidade do dinâmico mundo em que vivem. Entender a constituição de grupos também é essencial para desnaturalizar entidades raciais assumidas pelo senso comum como categorias de análise. Brancos, pretos e pardos são categorias raciais que podem servir de base para a formação de grupos, mas não são necessariamente o esteio comum e condutor de aglomeraçóes coesas em suas opinióes e atitudes. Ao se distinguir categorias de grupos, abre-se uma possiblidade investigativa para compreender como esses dois conceitos se relacionam e se condicionam mutuamente em contextos específicos. Pode-se perguntar, por exemplo, como processos políticos, sociais, culturais e psicológicos se alinham a determinadas categorias (exemplo, classe e raça), para gerar afinidade (groupness) entre os membros que delas fazem parte (Petersen, 1987; Brubaker, 2002, p. 12).

O objetivo deste artigo é investigar se a cor autodeclarada, além de delimitar grupos raciais categóricos, também é responsável pela formação de grupos com opinióes coesas (groupness) sobre temas diretamente atrelados à temática racial no Brasil. Investigaremos se as pessoas autodeclaradas brancas, pardas e pretas, além de constituírem categorias raciais, também constituem grupos com opinióes e ideais compartilhados. Para averiguarmos a existência de groupness entre grupos raciais - que por si sós possuem muitas dimensóes -, usaremos como referência teórica o paradigma das fronteiras raciais (tanto sociais, quanto simbólicas), desenvolvido por Lamont e Molnár (2002). É através da permeabilidade de tais fronteiras, que grupos são formados e extintos, conforme a afinidade e similaridade de opinióes, atitudes e atributos que caracterizam estas fronteiras. Empiricamente, operacionalizaremos a fluidez dessas fronteiras, comparando o status so- cioeconômico (fronteira social) dos brancos, pardos e pretos e, também, a sua concordância quanto às percepçóes sobre racismo, miscigenação e política de cotas raciais (fronteiras simbólicas). Além de avaliar o papel da raça na delimitação de fronteiras simbólicas (tal como feito por Lamont et al., 2016), o presente trabalho investiga como as demarcaçóes sociais (ex. a classe econômica) interagem com as raciais, para configurarem grupos com opinióes similares. A estratégia adotada revela que classes sociais são mais determinantes do que a raça, para o estabelecimento de fronteiras simbólicas, delimitadoras de grupos similares de opinião.

À luz da tradição literária sobre os pardos nas relações raciais brasileiras (Degler, 1971; Skidmore, 1993), e de estudos recentes que mobilizam tal discussão (Daflon et al., 2017; Daflon, 2014; Moraes Silva e Leão, 2012), nossa hipótese é de que as atitudes dos pardos, por representarem categorias intermediárias de cor e com maior grau de mobilidade entre os dois extremos cromáticos (Miranda, 2014; Senkevics, 2017; Silveira et al., 2018), serão mais fluidas do que as de outros grupos raciais. Dependendo da fronteira em questão, seja social ou simbólica, investigaremos se pardos alinharão suas atitudes com brancos, pretos ou ambos; dissolvendo, assim, a fronteira racial e criando uma identidade de grupo que extrapolaria aquela da raça autodeclarada, evidenciando, desse modo, a sua fluidez. Entende-se, portanto, que as opinióes de indivíduos pardos não sejam monolíticas, e que haja diferenças atitudinais entre os autodenominados pardos - situados em classes baixas ou altas -, mais expressivas do que aquelas constatadas entre brancos, ou entre pretos de classes diferentes. Para investigar em que medida se alinham as fronteiras raciais, sociais e simbólicas, operacionalizamos o conceito de groupness por meio de variáveis padronizadas, que expressam níveis distintos de atitudes raciais. A metodologia proposta se diferencia daquela de estudos anteriores (Bailey, 2002, 2004, 2009; Bailey; Fialho e Peria, 2015), sobretudo por investigar se o pertencimento racial autodeclarado converge com múltiplas dimensões simbólicas comparáveis em suas intensidades simultaneamente definidas.

O presente artigo está organizado em três partes. A primeira introduz o paradigma teórico das fronteiras sociais e simbólicas, para analisar a dinâmica de 
formação de grupos (groupness). Para isso, retomamos o debate sobre classe e raça no Brasil, com destaque para o entendimento dos pardos e suas atitudes. A segunda apresenta os dados, as variáveis e a metodologia utilizados para operacionalizar nossa análise. Por último, apresentamos os resultados da pesquisa, seguidos de uma discussão e breve conclusão.

\section{Referencial teórico}

\section{Fronteiras raciais e formação de grupos}

Segundo Lamont e Molnár (2002), fronteiras são, a rigor, formas de categorização e de hierarquização de comportamentos e práticas, a partir das quais grupos identitários se autodefinem e definem regras de constrangimento do agir social, inclusão ou exclusão. Sua utilização, como perspectivas analíticas, envolve a articulação entre condições simbólicas e materiais de delimitação do espaço de constrangimento desse agir, trazendo à baila estruturas e relaçóes de poder construídas histórica e cotidianamente. Ao funcionarem como linhas delimitadoras, portanto, as fronteiras fazem sentido como perspectivas de análise das relaçóes entre grupos sociais, pautadas ora pela partilha, ora pela distinção. Mas, uma vez que envolvem restriçóes, tanto de ordem material quanto simbólica, seria adequado assumir o conceito de fronteiras como um monólito?

Lamont e Molnár (2002) também nos oferecem respostas a esse respeito, ao dividirem o conceito em fronteiras simbólicas e sociais. Fronteiras simbólicas seriam distinçóes conceituais da realidade e das relações entre grupos sociais, a partir da categorização de pessoas, objetos, práticas, do tempo e do espaço; bem como seriam importantes pistas para a compreensão sobre como diferentes grupos sociais reproduzem sistemas de categorização e prestígio. Elas são, então, critérios de distinção adotados para se ordenar pessoas em grupos, segundo sentimentos e símbolos compartilhados, incluindo-se aqui as práticas culturais e outras formas horizontais de sociabilidade inter-racial (casamento, relaçóes de amizade e opinióes compartilhadas, por exemplo).

Fronteiras sociais, por outro lado, seriam a expressão objetiva e material desses sistemas de dife- renças que se manifestam nas diferenças de acesso a recursos e oportunidades. Seriam caracterizadas por hierarquias verticais de poder socioeconômico, e verificadas por medidas de desigualdades sociais (e raciais). Resumindo: se, por um lado, as fronteiras simbólicas orientam comportamentos "normais" e "desviantes", como também o que é digno de status e o que não o é, as fronteiras sociais são consequências materiais disso: como o acesso à universidade, à participação política etc.

A compreensão do conceito de fronteiras sejam elas simbólicas ou sociais - é fundamental para entender a formação, a consolidação e a dissolução de grupos sociais, para além dos critérios socioeconômicos que os definem (a classificação racial sendo um deles). Isto é, para além dos aspectos puramente estatísticos e objetivos que orientam a designação de indivíduos a determinados grupos sociais, a definição de fronteiras importa para compreender a vivência em um determinado grupo, a partir desses aspectos.

Por isso, na medida em que os processos sociais, que condicionam a flutuação de fronteiras, condicionam igualmente o entendimento de como e por que grupos com identidades compartilhadas se formam, torna-se útil adotar o paradigma das fronteiras sociais e simbólicas. Para compreender a dinâmica de diferenças sociais institucionalizadas - como, por exemplo, as de classe, raça, religião, gênero, desigualdade e participação política -, é fundamental avaliar como agrupamentos são formados e dissolvidos através da construção, cruzamento e deslocamento de fronteiras constituídas a partir de ideologias, status, opiniōes e valores compartilhados.

Sendo assim, a definição de fronteiras (simbólicas ou sociais) toma emprestado um construto conceitual auxiliar e intrinsecamente relacionado: o de groupness, que pressupóe o senso de pertencimento a um grupo formado por laços de solidariedade e marcas de distinção em relação a outros grupos (Brubaker, 2002; Loveman, 1999). Na aplicação da definição de fronteiras e groupness ao estudo sobre relaçōes raciais, é importante considerar que a forma de utilização destes conceitos depende, em grande medida, da posição que o conceito de raça ocupa no debate social e, especialmente, da maneira como se vive, na prática, a experiência da categorização racial. 
A fluidez atitudinal dos pardos: da válvula de escape à permeabilidade de fronteiras

Há quase meio século, Carl Degler (1971) argumentou que a principal diferença entre os esquemas raciais americano e brasileiro estava na manutenção dos pardos (mulattos) como uma opção racial no Brasil. Enquanto nos Estados Unidos os que antes eram percebidos como pardos foram socialmente, politicamente, legalmente e estatisticamente assimilados como pretos (blacks), no Brasil, no começo do século vinte, eles continuaram ocupando um lugar à parte:

Tal lugar não é reservado àqueles considerados como miscigenados (mixed blood) nos Estados Unidos; uma pessoa é ou preta (black) ou branca (white). Por isso, o mulato no Brasil representa uma válvula de escape para o Negro, por assim dizer, que não está disponível nos Estados Unidos (Degler, 1971, p. 107, tradução nossa).

A diferença primária entre os regimes raciais brasileiro e estadunidense seria a figura do "nem preto nem branco", cuja posiçáo intermediária, marcada por uma fluidez classificatória peculiar, seria empregada nos momentos mais convenientes (Degler apud Guimarães, 1999). Para Degler, a válvula de escape dos mulatos, ainda que gerada de forma inconsciente e não intencional, ajudaria a explicar por que as relaçóes raciais no Brasil seriam menos rígidas e hostis, do que no caso americano. Ao literalmente misturar as raças, os pardos concomitantemente atenuariam a linha racial entre brancos e pretos.

A tese de Degler descreve, sobretudo, como os mestiços (pardos) cruzavam fronteiras materiais e eram mais facilmente assimilados aos brancos, do que os pretos: "Historicamente, é o mulato quem ascende na sociedade brasileira, não o Negro" [...]. É o mulato que é socialmente móvel, não o Negro" (Degler, 1971, p. 107-109, traduçáo nossa). Entretanto, além de os pardos se moverem com maior facilidade entre as fronteiras sociais, o caminho inverso - ou seja, a ideia segundo a qual a mobilidade social permitiria o branqueamento - está igualmente presente em sua obra:
Um mulato rico é aceito pelos brancos em um grau que um mulato pobre não o é. [...] Uma vez embranquecido pelo dinheiro, um Negro torna-se mulato ou pardo, independentemente da sua cor atual (Degler, 1971, p. 105, tradução nossa).

$\mathrm{Na}$ visão do autor, a mobilidade social ascendente seria capaz de alterar as linhas raciais percebidas, clareando-as. Ao cruzarem a fronteira social, pretos e pardos poderiam também cruzar as fronteiras raciais. A dinâmica descrita por Degler pressupóe, portanto, que classe e raça seriam interdependentes: pessoas percebidas como mais claras ascenderiam socialmente com maior facilidade, e tal ascensão, por sua vez, permitiria a elas permear ou "transcender" ao mundo dos brancos. A "válvula de escape" refere-se, assim, primordialmente, a um processo de mobilidade econômica, mas que seria também capaz de reconfigurar as linhas raciais percebidas. A partir dos conceitos de Lamont e Molnár (2002), seria entáo possível dizer que a "válvula de escape do mulato" catalisaria não apenas mudanças da fronteira social, mas também amenizaria tensōes raciais ao alterar a fronteira racial, enquadrando-se e funcionando, assim, simultaneamente, como uma deslocadora das fronteiras simbólicas:

A válvula de escape do mulato serve como um símbolo, capaz de condensar relacionamentos e atitudes entre pretos e brancos. Ao voltarmos nossa atenção para tal símbolo, e explicarmos o seu desenvolvimento histórico, somos também capazes de explicar várias atitudes a padróes comportamentais representados e explicados por ele (Degler, 1971, p. 225).

A categoria de cor intermediária, ao tornar incerto e complexificar o desenho do continuum racial entre os polos branco e preto, acabaria por absorver pessoas dos dois lados, mantendo-se como uma possibilidade para ambos. Talvez por isso, "a cor parda ainda hoje consta no censo brasileiro, e mais parece um 'nenhuma das anteriores', um grande etcetera ou um coringa da classificação" (Schwarcz e Starling, 2015, p. 94).

Como o interesse do presente artigo reside em analisar a permeabilidade das fronteiras raciais sim- 
bólicas e sociais no Brasil, recorrer aos pardos como grupo de foco é inevitável, uma vez que eles estão espacialmente no intermédio destas fronteiras, em uma situação que lhes permite transitar entre elas, a partir de critérios que envolvem identidades raciais (pertinentes às fronteiras simbólicas) e interesses materiais (referentes às fronteiras sociais).

O paradigma da "válvula de escape", como mecanismo orientador do emprego prático da identificação racial dos pardos, poderia ser assim complementado pela análise de como as fronteiras simbólicas e sociais permeiam as atitudes desses indivíduos, exatamente a partir da compreensão de que os pardos, pela complexidade de sua posição no continuum de cor, também apresentam traços identitários complexos, e que merecem atenção a partir de uma lógica que articule características simbólicas e de oportunidades. Ao se adotar o paradigma das fronteiras, permite-se ao pardo mover-se tanto para o lado dos pretos quanto para o dos brancos, diferentemente da perspectiva unidirecional e economicamente condicionada do branqueamento, adotada por Degler (1971).

Nesse cenário, trabalhos como o de Daflon et al. (2017), Daflon (2014), e Moraes Silva e Leão (2012) buscam - a partir da constatação de que os pardos são, frequentemente, um público ignorado pelo interesse acadêmico, por suas características identitárias - questionar o retrato dos pardos como "atípicos", ou movidos essencialmente por interesses em sua classificação. Além de lançar luz sobre a interlocução entre a identidade parda e os polos do continuum racial, essa nova geraçáo busca colocar em xeque definiçóes essencialmente voluntaristas da formação e consolidação de identidades sociais (Daflon, 2014).

Sob o pressuposto de que opinióes compartilhadas são uma forma de solidariedade e, portanto, um dos esteios da noção de groupness, a fluidez dos pardos também se manifestaria na inexistência (ou na baixa existência) de groupness racial no Brasil (Bailey, 2009). Exemplo disso é que, quando incitados a se autoclassificarem como brancos ou pretos, $40 \%$ dos pardos se identificam com a primeira categoria (Bailey, 2009). Na linha desse raciocínio, Muniz $(2012,2016)$ verificou persistentes inconsistências de categorização racial, principalmente per- vasivas aos indivíduos classificados como pardos; análise também feita (mas de forma qualitativa) por Moraes Silva e Leão (2012).

Essa fluidez poderia, a princípio, ser vista como um aspecto reforçador de que a groupness racial de indivíduos pardos oscilaria entre a liberdade positiva, oriunda da facilidade de trânsito, e a dificuldade de categorização racial em termos formais. Nos Estados Unidos, ${ }^{2}$ por exemplo, cerca de $9 \%$ das pessoas classificadas como Black, no censo populacional de 1870, foram reclassificadas como Mulattos, em 1880. A mesma proporção fez o caminho contrário, passando de Mulatto para Black, durante o mesmo período. Somadas, estas duas proporçóes correspondem a $18 \%$ de mudança racial classificatória. Entre 1880 e 1910/1920, o percentual de mudança racial foi ainda mais considerável, aumentando para cerca de 22\% de pessoas (Saperstein e Gullickson, 2013 , p. 1933). Tal padrão de reclassificação racial se manteve no final do século vinte, de acordo com dados longitudinais observados entre 1979 e 2002 (Saperstein e Penner, 2012). Além disso, 6,1\% (cerca de 10 milhóes de pessoas) dos entrevistados tiveram reportadas, no censo americano de 2010, raças distintas daquelas declaradas em 2000 (Liebler et al., 2017). No entanto, é provável que, mesmo no caso americano, tal dificuldade de categorização seja cada vez menor, devido à possibilidade de marcação de raças múltiplas. No censo americano de 2000, por exemplo, 2,4\% das pessoas se autoclassificaram como mestiças (mixed race) e, em 2010, 2,9\% marcaram mais de uma raça. Estes percentuais, entretanto, são ainda muito pequenos, para se afirmar que a one drop rule, estabelecida em 1920, deixou de ser a norma vigente.

No contexto brasileiro, dados longitudinais recentes sobre reclassificação racial, oriundos da Pesquisa Mensal de Emprego (Miranda, 2014), do Enem (Senkevics, 2017) e da RAIS/ MTE (Silveira et al., 2018), mostram que a categoria racial parda ainda é, de fato, a que possui os maiores fluxos de mudança. Miranda (2014, p. 88) demonstra que em períodos de nove meses, observados entre 2002 e 2014, 22,9\% dos respondentes mudaram de raça. Do total dos autodenominados pardos, $19,6 \%$ se reclassificaram como brancos e $8 \%$ como pretos, na segunda entrevista $(72 \%$ permaneceram par- 
dos). Dos autodenominados "pretos", na primeira entrevista, 30,6\% se reclassificaram como pardos e 7,6\%, como brancos. E do total de "brancos", $14,6 \%$ se reclassificaram como pardos e 1,4\%, como pretos. Senkevics (2017) também mostra que os maiores fluxos reclassificatórios ocorrem entre pardos e alguma outra categoria racial. Mais especificamente, em mais de um ano, 21,7\% dos que se inscreveram no ENEM mudaram sua autoclassificação de cor, entre 2010-2014, dos quais 18,4\% foram fluxos de, ou para a raça parda. Por fim, Silveira et al. (2018) constata que, entre 2008 e 2015 , $11,5 \%$ foram racialmente reclassificados, sendo $10,3 \%$ das classificaçóes de origem ou destino para a categoria dos pardos.

Essas evidências sugerem que cerca de um quinto das populaçóes pesquisadas mudam a autodeclaração racial, ao longo do tempo, e que aproximadamente um décimo muda sua raça heteroclassificada na RAIS. Destes percentuais, mais de $85 \%$ são mudanças raciais para, ou da categoria dos pardos para alguma outra, corroborando, assim, a ideia de que os pardos são os que possuem a maior fluidez entre fronteiras raciais preestabelecidas.

$\mathrm{O}$ desdobramento das fronteiras raciais, em simbólicas e sociais, tem permitido conciliar as visóes preconizadas pela primeira geração dos estudos raciais brasileiros, e consolidadas no paradigma da democracia racial, com os retratos feitos pelos analistas das desigualdades raciais e sociais, tributários da escola estrutural-funcionalista; sobretudo, a partir da articulação entre identidades raciais e de classe, mediadas por interesses também raciais e de classe. Daflon et al. (2017), por exemplo, ressaltam a divergência entre os efeitos da discriminação racial, na mobilidade social de indivíduos pardos, e a baixa percepção qualitativa de discriminação expressa por eles - aspecto também investigado por Moraes Silva e Leão (2012), que, entretanto, sinalizam que tal fluidez não impede os pardos de se solidarizarem e também denunciarem a intolerância racial.

O uso das fronteiras simbólicas e sociais, em franca ascensão no campo das relaçóes raciais no Brasil, parece ser uma chave para decifrar a aparente fluidez atitudinal dos indivíduos pardos no país. Ao admitirmos a coexistência entre essas fronteiras, não como um sinal de oportunismo, mas sim como um retrato da penetração das estruturas sociais sobre estas mesmas atitudes, conciliamos as "áreas duras" e "áreas moles" das relaçôes raciais no Brasil (Sansone, 1996), ou as dimensóes de assimilação horizontais e verticais (Telles, 2003). Sendo assim, devido à sua habilidade de fluir livremente entre as duas polaridades de cor, sem serem estigmatizados, os pardos seriam flexibilizadores primordiais de fronteiras, podendo alterá-las simbolicamente, sem cruzarem, necessariamente, as categorias raciais que os delimitam.

Ao investigar a permeabilidade das fronteiras simbólicas - clivagens que não se referem à esfera material da vida social, mas sim a espaços de ordem simbólica, tais como experiências de segregação, a formação de laços de amizade, casamento, e diferenças entre repertórios culturais (Lamont et al., 2016; Lamont e Molnár, 2002; Moraes Silva e Leão, 2012; Moraes Silva e Reis, 2015) -, analisaremos especificamente a capacidade de os indivíduos pardos atuarem como operadores dessas fronteiras. Investigaremos a formação de fronteiras simbólicas e grupos de afinidade, por meio das opiniôes compartilhadas de brancos, pretos e pardos, sobre racismo, miscigenação e apoio às cotas raciais, considerando, assim, não só os múltiplos significados que a identificação como pardo adquire para quem opta por ela; como também o reconhecimento de que a categorização racial no Brasil náo descortina suficientemente o real significado do pertencimento a cada ponto no continuum de cor. Exploraremos, portanto, a diversidade da identidade parda, baseando-nos na percepção daqueles que se identificam dessa maneira, pela constataçáo de que "os pardos não são simplesmente menos negros” (Moraes Silva e Leão, 2012, p. 131).

A curiosidade que orienta o nosso estudo propõe a seguinte indagação: os pardos teriam um padrão de atitudes raciais diferente do padrão dos brancos e dos pretos? Nossa hipótese é a de que os indivíduos pardos, por ocuparem uma posição intermediária no espectro de cor, teriam uma identidade de grupo mais maleável, apresentando atitudes raciais ora semelhantes às dos brancos, ora semelhantes às atitudes dos pretos, ora convergentes com as de ambos. 


\section{Dados e métodos}

Nosso estudo usou como fonte de informação o banco de dados Racismo Cordial, coletado e organizado pelo Instituto Datafolha, em setembro de 2008. A pesquisa entrevistou, em 213 municípios, 2982 indivíduos pertencentes a ambos os sexos, de todas as classes sociais e de todas as regióes do país (Datafolha, 2008). ${ }^{3}$ Com o objetivo de investigar e monitorar o preconceito e o racismo no Brasil, explorando como tais fatores se manifestam em atitudes cotidianas dos entrevistados, essa pesquisa quantitativa deu continuidade àquela realizada em 1995, ano no qual o Instituto Datafolha entrevistou 5081 pessoas, em 121 cidades do país.

Para investigar a volatilidade e a concordância ideológica e racial da população brasileira, adotamos o paradigma das fronteiras, sugerido por Lamont e Molnár (2002). Operacionalizamos as fronteiras sociais e simbólicas, a partir de variáveis dependentes ordinais, com três categorias (baixa, média e alta) definidas conforme a Tabela 1 .

Cada uma das variáveis dependentes representa a combinação de três outras variáveis coletadas pela pesquisa e padronizadas para representarem uma escala ordinal. As medidas de fronteiras simbólicas e sociais foram construídas a partir das médias das variáveis que compóem cada uma delas. As variáveis utilizadas foram, quando necessário, categorizadas ou recodificadas para possuírem escalas equivalentes, permitindo, assim, a sua combinação através da média. ${ }^{4}$ No caso da fronteira social, por exemplo, a categoria "baixa" representa $36 \%$ dos que se encontram em posiçóes relativamente inferiores de renda, escolaridade e posse de bens duráveis (por exemplo, o Critério Brasil). A renda captada pelo questionário é intervalar e foi recodificada em baixa, média ou alta, da seguinte forma: $40 \%$ correspondem à primeira categoria (até 2 salários mínimos); $40 \%$ correspondem àqueles que recebem entre 2 e 5 salários mínimos; e os $20 \%$ restantes correspondem aos que recebem mais de cinco salários mínimos. As variáveis de escolaridade e consumo (Critério Brasil) também foram categorizadas em três níveis, para poderem ser combinadas com a renda através da média.

O "Critério (de Classificação Econômica) Brasil" é uma medida sugerida pela Associação Brasi- leira de Empresas de Pesquisa (2010), para estimar o poder de compra das pessoas e famílias urbanas, a partir da construção de "classes econômicas" definidas segundo a posse de bens duráveis de consumo (televisão, rádio, geladeira, automóvel, máquina de lavar e outros). ${ }^{5}$ Para combiná-la com as categorias de renda e escolaridade, nós calculamos os seus tercis para obter categorias baixa, média e alta de consumo. O passo final para a construção da fronteira social consistiu em calcular a média das variáveis tricotômicas de renda, escolaridade e consumo, captada pelo Critério Brasil.

No caso das fronteiras simbólicas, a escala de três níveis de intensidade (baixa, média e alta) representa o grau de concordância com ideias relativas a racismo ${ }^{6} 7$, mistura racial e apoio às cotas raciais. Operacionalizamos a intensidade do groupness, a partir da diferença entre as probabilidades preditas de concordância com cada um dos níveis de intensidade das fronteiras simbólicas propostas. Assumimos que, quanto maior a diferença entre as probabilidades preditas por raça, menor será o groupness racial; e quanto menor a diferença entre as probabilidades preditas, maior será o grau de coesão interracial - ou seja, maior será o groupness. A distribuição das médias e desvios-padrão das variáveis utilizadas nos modelos encontra-se na Tabela 1 .

A tabela mostra que, em sua maioria, tanto brancos quanto pardos e pretos possuem baixa concordância com frases de cunho racista (fronteira simbólica 1); possuem baixa discordância quanto aos benefícios de ser ter uma sociedade racialmente diversa (fronteira simbólica 2); e dão "alto" apoio às cotas raciais (fronteira simbólica 3). Entretanto, para avaliar a similaridade interracial das proporções apresentadas, é necessário examinar as análises multivariadas, descritas na próxima seção.

Por fim, cabe esclarecer que a variável raça é utilizada aqui como categoria de análise; como um "conceito analítico nominalista", mas derivado e construído a partir de um "conceito nativo", a cor da pele (Guimarães, 2003, p. 98, 104). Ao adotarmos a raça como uma categoria analítica, compartilhamos do difícil dilema entre empiria e construtivismo social. Por um lado, ao categorizarmos a raça, assumimos que ela tem uma dimensão objetiva e existente, que nos 
Tabela 1

Descrição das Variáveis de Interesse

\begin{tabular}{|c|c|c|c|c|}
\hline $\begin{array}{l}\text { Variáveis originais } \\
\text { utilizadas }\end{array}$ & Pergunta do questionário & $\begin{array}{l}\text { Mensuração } \\
\text { original }\end{array}$ & $\begin{array}{l}\text { Mensuraçáo } \\
\text { derivada }\end{array}$ & $\begin{array}{l}\text { Variável dependente } \\
\text { derivada }\end{array}$ \\
\hline Escolaridade & $\begin{array}{l}\text { "P71. Até que ano da escola } \\
\text { você estudou?" }\end{array}$ & $\begin{array}{c}\text { Categórica ordinal, } \\
1-4\end{array}$ & \multirow{3}{*}{$\begin{array}{l}\text { 0=baixa; } \\
\text { 1=média; } \\
\text { 2=alta }\end{array}$} & \multirow{3}{*}{$\begin{array}{l}\text { Classe/ fronteira } \\
\text { social }\end{array}$} \\
\hline Renda & $\begin{array}{l}\text { "P76. Somando a sua renda } \\
\text { com a renda das pessoas que } \\
\text { moram com vocế, quanto é } \\
\text { aproximadamente a renda } \\
\text { familiar mensal na sua casa, } \\
\text { segundo esse cartão?" }\end{array}$ & $\begin{array}{c}\text { Categórica ordinal, } \\
1-7\end{array}$ & & \\
\hline Critério Brasil & $\begin{array}{l}\text { Variável derivada a partir } \\
\text { das perguntas } 69 \text { a à } 69 \mathrm{q} \text {, } \\
\text { sobre a posse e quantidade } \\
\text { de bens duráveis presentes no } \\
\text { domicílio. }\end{array}$ & Escalar, $0-46$ & & \\
\hline \multirow{3}{*}{$\begin{array}{l}\text { "Vou dizer algumas } \\
\text { coisas que as pessoas } \\
\text { costumam falar e } \\
\text { gostaria que você } \\
\text { dissesse se concorda } \\
\text { ou discorda de cada } \\
\text { uma das ideias" }\end{array}$} & $\begin{array}{l}\text { "P4a. Você concorda ou } \\
\text { discorda que negro bom } \\
\text { é negro de alma branca? } \\
\text { Totalmente, ou em parte?" }\end{array}$ & $\begin{array}{c}\text { Categórica ordinal, } \\
1-5\end{array}$ & \multirow{3}{*}{$\begin{array}{l}\text { 0=baixa; } \\
\text { 1=média; } \\
\text { 2=alta }\end{array}$} & \multirow{3}{*}{$\begin{array}{l}\text { Fronteira simbólica } \\
1 \text { - racismo }\end{array}$} \\
\hline & $\begin{array}{l}\text { "P4c. Você concorda ou } \\
\text { discorda que as únicas coisas } \\
\text { que os negros sabem fazer } \\
\text { bem são música e esporte? } \\
\text { Totalmente, ou em parte?" }\end{array}$ & $\begin{array}{c}\text { Categórica ordinal, } \\
1-5\end{array}$ & & \\
\hline & $\begin{array}{l}\text { "P4i. Você concorda ou } \\
\text { discorda que negro quando } \\
\text { não faz besteira na entrada, } \\
\text { faz na saída? Totalmente, ou } \\
\text { em parte?" }\end{array}$ & $\begin{array}{c}\text { Categórica ordinal, } \\
1-5\end{array}$ & & \\
\hline \multirow{3}{*}{$\begin{array}{l}\text { "Vou dizer algumas } \\
\text { coisas que as pessoas } \\
\text { costumam falar e } \\
\text { gostaria que você } \\
\text { dissesse se concorda } \\
\text { ou discorda de cada } \\
\text { uma das ideias" }\end{array}$} & $\begin{array}{l}\text { "P4b. Você concorda ou } \\
\text { discorda que uma boa coisa } \\
\text { do povo brasileiro é a mistura } \\
\text { de raças? Totalmente, ou em } \\
\text { parte?" }\end{array}$ & $\begin{array}{c}\text { Categórica ordinal, } \\
1-5\end{array}$ & \multirow{3}{*}{$\begin{array}{l}\text { 0=baixa; } \\
\text { 1=média; } \\
\text { 2=alta }\end{array}$} & \multirow{3}{*}{$\begin{array}{l}\text { Fronteira simbólica } \\
2 \text { - mistura racial }\end{array}$} \\
\hline & $\begin{array}{l}\text { "P4f. Você concorda ou } \\
\text { discorda que é bom para uma } \\
\text { sociedade que ela seja feita de } \\
\text { pessoas de diferentes raças? } \\
\text { Totalmente, ou em parte?" }\end{array}$ & $\begin{array}{c}\text { Categórica ordinal, } \\
1-5\end{array}$ & & \\
\hline & $\begin{array}{l}\text { "P4g. Você concorda ou } \\
\text { discorda que pessoas de } \\
\text { raças diferentes não devem } \\
\text { se casar? Totalmente, ou em } \\
\text { parte?" }\end{array}$ & $\begin{array}{c}\text { Categórica ordinal, } \\
1-5\end{array}$ & & \\
\hline
\end{tabular}

continua. 
Tabela 1

Descrição das Variáveis de Interesse

\begin{tabular}{|c|c|c|c|c|}
\hline $\begin{array}{l}\text { Variáveis originais } \\
\text { utilizadas }\end{array}$ & Pergunta do questionário & $\begin{array}{l}\text { Mensuração } \\
\text { original }\end{array}$ & $\begin{array}{l}\text { Mensuraçáo } \\
\text { derivada }\end{array}$ & $\begin{array}{l}\text { Variável dependente } \\
\text { derivada }\end{array}$ \\
\hline $\begin{array}{l}\text { Apoio às cotas raciais } \\
\text { nas universidades }\end{array}$ & $\begin{array}{l}\text { "P9. Você é a favor ou contra } \\
\text { as cotas; isto é, que sejam } \\
\text { reservadas vagas para negros } \\
\text { e descendentes de negros nas } \\
\text { universidades?" }\end{array}$ & $\begin{array}{l}\text { Categórica nominal, } \\
1-3\end{array}$ & \multirow{3}{*}{$\begin{array}{l}\text { 0=baixa; } \\
\text { 1=média; } \\
\text { 2=alta }\end{array}$} & \multirow{3}{*}{$\begin{array}{l}\text { Fronteira simbólica } 3 \\
\text { - apoio às cotas raciais }\end{array}$} \\
\hline $\begin{array}{l}\text { Apoio às cotas raciais } \\
\text { nas empresas }\end{array}$ & $\begin{array}{l}\text { "P10. E você é a favor ou } \\
\text { contra que sejam reservadas } \\
\text { vagas nas empresas para } \\
\text { negros e descendentes de } \\
\text { negros?" }\end{array}$ & $\begin{array}{l}\text { Categórica nominal, } \\
1-3\end{array}$ & & \\
\hline $\begin{array}{l}\text { Cotas raciais são } \\
\text { fundamentais }\end{array}$ & $\begin{array}{l}\text { "P12c. As cotas para negros } \\
\text { nas universidades são } \\
\text { fundamentais para ampliar } \\
\text { o acesso de toda a população } \\
\text { à educação. Concorda } \\
\text { ou discorda desta frase? } \\
\text { Totalmente, ou em parte?" }\end{array}$ & $\begin{array}{l}\text { Categórica ordinal, } \\
1-5\end{array}$ & & \\
\hline
\end{tabular}

Fonte: Elaboração própria, com base em Datafolha (2008).

permite observá-la e medi-la. Mas, por outro lado, reconhecemos que os significados de raça resultam de processos sociais múltiplos, fluidos e dinâmicos. Como a raça contêm categorias socialmente construídas, o seu significado é passível de mudança tanto no tempo quanto no espaço, dependendo seja de quem o utiliza, como do propósito social ou político para o qual ele é empregado. Logo, ao mesmo tempo em que rejeitamos a visão essencialista de raça, adotamos categorias autopercebidas de cor da pele, para podermos identificar e, quiçá, iluminar alguns dos padróes reais que orientam a experiência da vida cotidiana. Com esta ressalva em mente, captamos e construímos a categoria raça a partir da declaração dos entrevistados ao questionário fechado da Pesquisa do Instituto Datafolha (2008), que utilizou a seguinte pergunta: "Considerando as seguintes categorias, qual é a sua cor?” Das doze opçóes reportadas, as mais prevalentes foram "Branca", "Parda" e "Preta", que contabilizaram, respectivamente, cerca de 37\%, 36\% e 15\% do total de respostas. As pessoas que marcaram as opçóes "Mulato" (0,13\%), "Moreno" (4,05\%) ou "Moreno claro" $(0,44 \%)$ foram incorporadas à categoria dos autodeclarados pardos; e as que marcaram "Negro" (0,10\%) ou "Moreno escuro" (0,03\%) foram fundidas à dos pretos. As opçóes "Amarela" (2,77\%), "Indígena" (4,69\%) e "Outras respostas" (0,20\%) não foram consideradas na análise.

\section{Metodologia}

Para investigar a associação entre as quatro variáveis respostas, cor e classe social, controlando-se por covariáveis relevantes (sexo, idade, região), utilizamos regressóes logísticas ordinais de chances proporcionais (Long e Freese, 2006; McCullagh, 1980; Powers e Xie, 2008). Tal modelagem utiliza a probabilidade acumulada de $Y$, que recai na faixa de interesse $k$, ou em faixas inferiores.

Devido à correlação existente entre raça e classe social, também consideramos modelagens logísticas ordinais de dados balanceados por classe 
Tabela 2

Distribuição de Medidas de Tendência Central e Dispersão das Variáveis Utilizadas nos Modelos de Regressão

\begin{tabular}{|c|c|c|c|c|c|c|}
\hline & \multicolumn{2}{|c|}{ Brancos } & \multicolumn{2}{|l|}{ Pardos } & \multicolumn{2}{|l|}{ Pretos } \\
\hline & média & (d.p.) & média & (d.p.) & média & (d.p.) \\
\hline \multicolumn{7}{|l|}{ Variáveis resposta: } \\
\hline \multicolumn{7}{|l|}{ Fronteira/ Classe Social } \\
\hline Baixa & 0,33 & $(0,47)$ & 0,38 & $(0,49)$ & 0,40 & $(0,49)$ \\
\hline Média & 0,48 & $(0,50)$ & 0,49 & $(0,50)$ & 0,47 & $(0,50)$ \\
\hline Alta & 0,20 & $(0,40)$ & 0,12 & $(0,33)$ & 0,13 & $(0,33)$ \\
\hline \multicolumn{7}{|c|}{ Fronteira Simbólica 1 - racismo } \\
\hline Baixa & 0,66 & $(0,47)$ & 0,66 & $(0,47)$ & 0,74 & $(0,44)$ \\
\hline Média & 0,28 & $(0,45)$ & 0,29 & $(0,45)$ & 0,22 & $(0,41)$ \\
\hline Alta & 0,06 & $(0,23)$ & 0,05 & $(0,22)$ & 0,04 & $(0,20)$ \\
\hline \multicolumn{7}{|c|}{ Fronteira simbólica 2 - mistura racial } \\
\hline Baixa & 0,79 & $(0,41)$ & 0,80 & $(0,40)$ & 0,80 & $(0,40)$ \\
\hline Média & 0,20 & $(0,40)$ & 0,19 & $(0,39)$ & 0,19 & $(0,39)$ \\
\hline Alta & 0,01 & $(0,10)$ & 0,01 & $(0,11)$ & 0,01 & $(0,10)$ \\
\hline \multicolumn{7}{|c|}{ Fronteira simbólica 3 - apoio às cotas } \\
\hline Baixa & 0,26 & $(0,44)$ & 0,24 & $(0,42)$ & 0,20 & $(0,40)$ \\
\hline Média & 0,30 & $(0,46)$ & 0,28 & $(0,45)$ & 0,31 & $(0,46)$ \\
\hline Alta & 0,44 & $(0,50)$ & 0,49 & $(0,50)$ & 0,49 & $(0,50)$ \\
\hline \multicolumn{7}{|l|}{ Covariáveis: } \\
\hline$\%$ Masculino & 0,49 & $(0,50)$ & 0,48 & $(0,50)$ & 0,50 & $(0,50)$ \\
\hline Idade & 40,18 & $(16,41)$ & 36,80 & $(15,64)$ & 36,43 & $(16,30)$ \\
\hline \multicolumn{7}{|l|}{ Regiáo } \\
\hline \% Sudeste & 0,47 & $(0,50)$ & 0,39 & $(0,49)$ & 0,44 & $(0,50)$ \\
\hline$\%$ Sul & 0,25 & $(0,43)$ & 0,09 & $(0,28)$ & 0,12 & $(0,32)$ \\
\hline$\%$ Nordeste & 0,19 & $(0,39)$ & 0,32 & $(0,47)$ & 0,31 & $(0,46)$ \\
\hline$\%$ Norte/ Centro Oeste & 0,10 & $(0,30)$ & 0,20 & $(0,40)$ & 0,13 & $(0,34)$ \\
\hline Tamanho amostral (n) & 1049 & & 1180 & & 415 & \\
\hline
\end{tabular}

Fonte: Elaboração própria, com base em Datafolha (2008). 
social e pelas demais covariáveis. Para isso, empregamos o método de pareamento difuso (coarsened exact matching, CEM), sugerido por Iacus, King e Porro (2012), para a condução de inferência causal. Entretanto, os resultados obtidos a partir desta estratégia foram análogos aos aqui apresentados, que não utilizam estratégias de balanceamento. Já os resultados utilizando dados pareados podem ser requeridos aos autores.

A equação geral do modelo é representada por:

$$
\operatorname{Logit}\left[P\left(Y_{j} \leq k \mid x\right)\right]=\ln \left[\frac{P\left(Y_{j} \leq k \mid x\right)}{P\left(Y_{j}>k \mid x\right)}\right]=\alpha_{k}-\beta X_{j}
$$

No modelo ordinal de chances proporcionais, o vetor de coeficientes independe das $k$-ésimas categorias da variável resposta $Y$. Os $k$ interceptos (ou pontos de corte) é que diferenciam as prediçóes para cada uma das categorias de $Y$ diante de um dado conjunto de valores de $x$ para o indivíduo $j$. Pressupóe-se, portanto, que a relação entre as variáveis independentes do vetor $X$ é a mesma em todas as categorias de $Y$, alterando-se apenas em função de variaçóes em pontos de corte . Nossa estratégia analítica consiste em, a partir desses modelos, estimar e comparar, para cada uma das fronteiras utilizadas, as probabilidades de pessoas brancas, pardas e pretas figurarem em cada um dos níveis ("baixa, média ou alta”) das variáveis respostas. Se as probabilidades preditas de brancas e pardas forem estatisticamente iguais em uma dada categoria, por exemplo, haverá evidência para corroborar a semelhança entre essas duas raças em uma dada fronteira. Se elas forem diferentes, a igualdade ou afinidade atitudinal entre raças será refutada. Pressupomos que opinióes convergentes definem grupos similares. Essa conjectura permeia, portanto, nossa análise. Os coeficientes estimados para cada um dos modelos especificados encontram-se em anexo.

\section{Resultados}

A fim de tornar a interpretação dos resultados intuitiva e acessível, optamos por apresentar as probabilidades preditas para "tipos ideais" específicos, bem como para cada categoria ordinal das variáveis dependentes. Por meio desse exercício contrafactual, estimamos probabilidades que, além de comparáveis entre si, representam a influência líquida da raça autodeclarada, já que todos os demais atributos considerados nos modelos são fixados em valores específicos. Além disso, para dar uma ideia da incerteza amostral atrelada às estimativas, tais probabilidades são apresentadas com seus respectivos erros-padrão, dando assim maior realismo ao conteúdo estatístico apresentado (King, Tomz e Wittenberg, 2000). Para exemplificar o procedimento, o quadro abaixo apresenta as probabilidades de mulheres brancas, pardas e pretas, da regiáo Sudeste, com idade média, localizarem-se nas classes sociais baixa, média e alta.

A terceira coluna da Tabela 3 apresenta as probabilidades preditas de cada grupo racial, ceteris paribus, estar em determinada classe social. As letras apresentadas na quinta coluna denotam as probabilidades que não são estatisticamente diferentes entre si. As mulheres pretas de classe baixa, e as pretas e pardas de classe média apresentam a letra $C$ na última coluna da tabela, indicando que a probabilidade média predita para as pretas de classe baixa não é estatisticamente distinta daquelas probabilidades preditas para as mulheres pardas e pretas de classe média, ao nível de 5\% de significância. As mulheres brancas de classe baixa e alta não compartilham letras com os pardos e nem com os pretos destas mesmas classes, o que indica que a probabilidade média predita para estas mulheres brancas seja significativamente diferente daquelas preditas para os outros dois grupos ao nível de 5\%.

A Tabela 3 mostra, ainda, que pessoas autodeclaradas brancas possuem menor probabilidade (30\%) de compor a classe baixa, do que pardas e pretas (37\% e 39\%, respectivamente). A última coluna da tabela indica probabilidades que são estatisticamente iguais. Em cada uma das classes sociais, pardas e pretas, por exemplo, possuem probabilidades estatisticamente iguais, já que compartilham a mesma letra. Isso indica que, tal como apontado por Silva (1978, 1979, 1980) e Souza, Ribeiro e Carvalhaes (2010, p. 87), pretos e pardos podem ser agrupados e tratados como membros de uma mesma categoria racial, quando o critério de referência se pauta na renda, na escolaridade e na posse de bens de consumo. Ainda 
Tabela 3

Comparação Estatística de Probabilidades Raciais Preditas Dentro da Fronteira Social

\begin{tabular}{|c|c|c|c|c|}
\hline \multirow[t]{2}{*}{ Classe social } & \multirow[t]{2}{*}{ Raça/cor } & \multicolumn{2}{|l|}{ Método-delta } & \multirow{2}{*}{$\begin{array}{l}\text { Bonferroni }{ }^{b} \\
\text { Grupos }\end{array}$} \\
\hline & & $\begin{array}{l}\text { Probabilidades } \\
\text { preditas }^{\text {a }}\end{array}$ & Erro-padrão & \\
\hline \multirow{3}{*}{ Baixa } & Branca & 0,300 & 0,018 & - \\
\hline & Parda & 0,372 & 0,019 & $\mathrm{~B}$ \\
\hline & Preta & 0,394 & 0,027 & $\mathrm{BC}$ \\
\hline \multirow{3}{*}{ Média } & Branca & 0,528 & 0,012 & $\mathrm{D}$ \\
\hline & Parda & 0,497 & 0,013 & $\mathrm{C}$ \\
\hline & Preta & 0,485 & 0,017 & $\mathrm{CD}$ \\
\hline \multirow{3}{*}{ Alta } & Branca & 0,172 & 0,013 & - \\
\hline & Parda & 0,131 & 0,011 & $\mathrm{~A}$ \\
\hline & Preta & 0,121 & 0,013 & A \\
\hline
\end{tabular}

Nota: Predições com a mesma letra na coluna "Grupos" são estatisticamente iguais ao nível de 95\% de confiança.

a Para assegurar que as probabilidades variem apenas de acordo com os atributos que se quer investigar (no caso, classe e raça), optamos por predizê-las para pessoas da região Sudeste, do sexo feminino e com idade média. Escolhemos estas categorias, apenas por elas representarem o "tipo ideal" mais prevalente na amostra investigada.

${ }^{\text {b }} \mathrm{O}$ método de Bonferroni é utilizado para computar p-valores e intervalos de confiança, considerando-se múltiplas comparaçóes entre as probabilidades preditas para cada categoria da variável ordinal utilizada. Uma das vantagens deste método, em comparação com outras alternativas (Sidák ou Scheffé), é que ele não requer tamanhos amostrais iguais e é considerado mais conservador do que outros métodos de ajuste, sobretudo quando se realiza um número grande de testes (StataCorp 2017, pp. 1514, 2088-89, 2108).

Fonte: Elaboração própria, com base em Datafolha (2008).

que as proporçóes raciais entre estratos sociais sejam distintas, não há diferenças significativas entre pardos e pretos dentro de cada estrato.

Sintetizando as diferenças raciais, dentro e entre cada uma das fronteiras adotadas, a Figura 1 mostra quão similares são as probabilidades raciais preditas entre pardos, brancos ou pretos, para cada uma das categorias ordinais das variáveis dependentes.

Diferenças de probabilidades próximas de zero indicam maior semelhança entre as raças, para uma dada categoria da variável dependente. No caso da fronteira social (figura do canto superior esquerdo), a evidência encontrada sugere que pardos e pretos são estatisticamente iguais em todas as classes sociais consideradas, já que os intervalos de confiança para a diferença entre probabilidades incluem o zero em todas as comparaçóes realizadas. Por outro lado, brancos e pardos não dividem as mesmas fronteiras sociais. A probabilidade de os brancos pertencerem à classe social média ou alta, por exemplo, é cerca de cinco pontos percentuais maior do que a dos pardos. Já a probabilidade dos pardos pertencerem à classe social baixa é aproximadamente sete pontos percentuais maior do que a dos brancos.

Os demais gráficos mostram que: brancos e pardos possuem o mesmo grau de con(dis)cordância com frases racistas (fronteira simbólica 1); brancos, pretos e pardos são igualmente favoráveis à mistura racial (fronteira simbólica 2) e às cotas raciais (fronteira simbólica 3), ainda que, neste último caso, a probabilidade de "alto" apoio às cotas dos pardos seja ligeiramente maior do que a dos brancos. Este último resultado, referente ao apoio às cotas, alinha-se àquele reportado por Bailey, Fialho e Peria (2015, p. 18), a partir 
Figura 1

Diferenças Interraciais das Probabilidades Intrafronteiras Sociais e Simbólicas
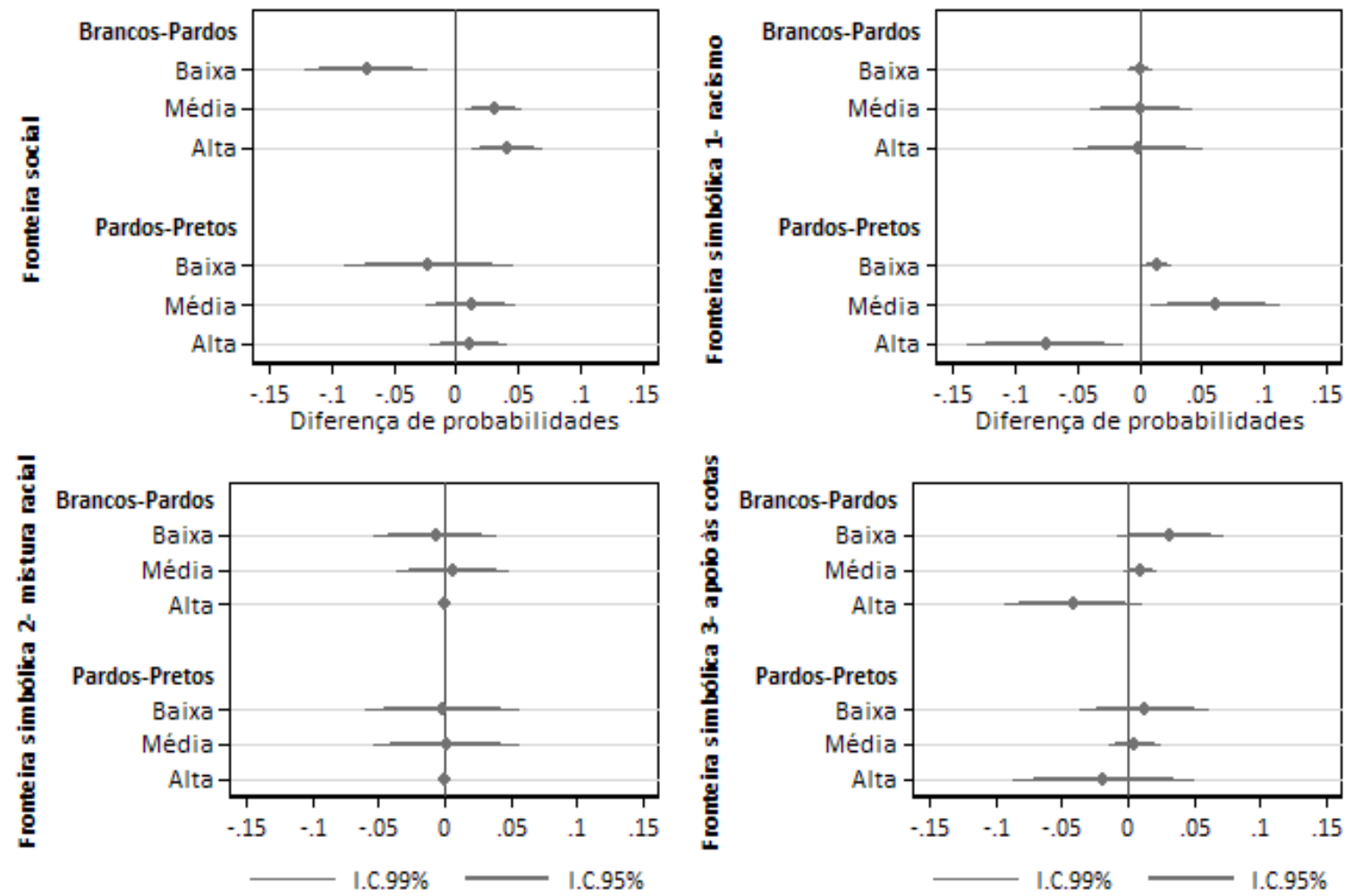

Fonte: Elaboração própria, com base em Datafolha (2008).

da análise dos dados do America’s Barometer, de 2010. Em termos de coesão de fronteiras, conclui-se, portanto, que os pardos são socialmente iguais aos pretos, mas simbolicamente iguais aos brancos ou iguais a ambos, dependendo do assunto em questáo.

A Figura 2 ilustra os impactos da raça e da classe nas atitudes dos brasileiros, no que se refere ao apoio às cotas raciais. Os efeitos da classe são mais fortes do que os da raça, e o mesmo se verifica em relação à mistura racial e à concordância com frases racistas. Os coeficientes de raça, como esperado da análise acima, sequer apresentam significância estatística (ver modelos completos, em anexo).

A Figura 2 evidencia que, para uma mesma classe social, não há diferenças entre os grupos raciais, no que se refere ao apoio às cotas. Brancos, pardos e pretos ricos, por exemplo, possuem probabilidades estatisticamente iguais de apoiar as cotas raciais. Entretanto, estas probabilidades variam consideravelmente, em função da classe social a que os grupos raciais pertencem. As pessoas ricas, por exemplo, independentemente da raça, possuem maior probabilidade (cerca de 45\%) de dar baixo apoio às cotas raciais, do que aquelas consideradas pobres (cerca de $15 \%$ ). Já a probabilidade de alto apoio às cotas é muito maior entre os pobres (cerca de 60\%), do que entre os ricos (cerca de 20\%). Esses resultados mostram que o efeito da classe social sobre as atitudes prevalece ao da raça, e que tal efeito é percebido em todas as raças de forma similar, refutando, assim, 


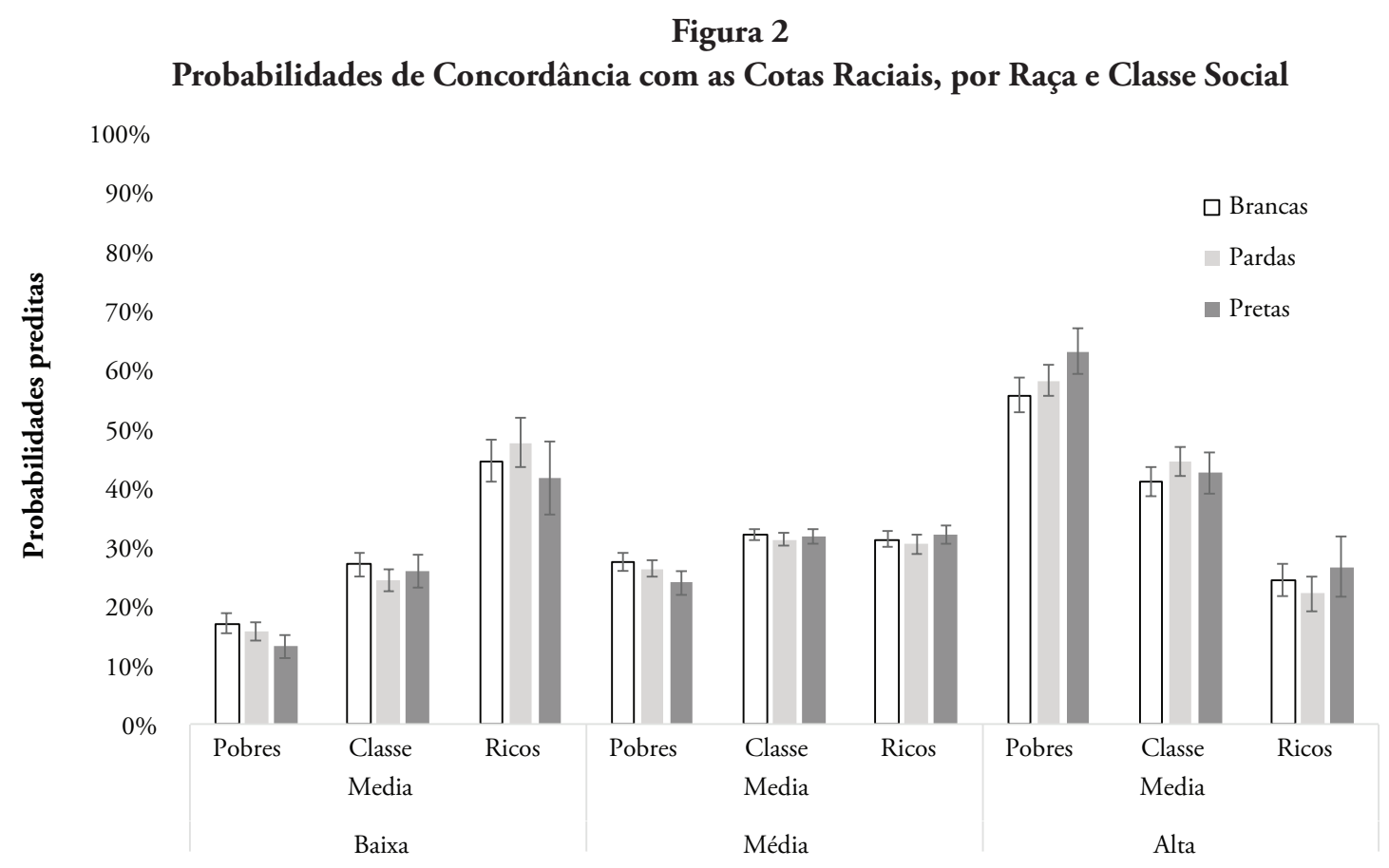

Concordância com as cotas raciais

Fonte: Elaboração própria, com base em Datafolha (2008).

a presença de um efeito diferencial de classe sobre a atitude dos pardos. A falta de significância estatística dos termos interativos entre raça e classe, inseridos nos modelos completos, também corrobora a mesma conclusão, que é igualmente válida para as demais atitudes ou fronteiras simbólicas consideradas. ${ }^{8}$

Entretanto, nossos resultados se baseiam em associaçôes contemporâneas que, devido à falta de ordem temporal dos eventos, são incapazes de desembaraçar a interrelação endógena entre raça e classe e isolar o impacto causal do status socioeconômico sobre a raça, juntando-se, assim, a outras evidências transversais sugestivas e sujeitas a argumentos de causalidade reversa (Bailey, Fialho, Peria, 2015; Marteleto, 2012; Schwartzman, 2007; Telles e Paschel, 2014).

\section{Discussáo}

Os primeiros escritos das Ciências Sociais brasileiras sobre as relaçôes raciais no país, consoante o paradigma vigente da democracia racial, preconizaram a diferenciação social no país como tributária da estrutura social, e não necessariamente da identificação racial (Buarque de Holanda, 1995; Freyre, 1973; Harris, 1964; Pierson, 1945; Wagley, 1952). Para os autores desse período, o campo da distinção na estrutura social seria estamental, e não necessariamente racial. As interpretações da época concluíram que a dissolução das fronteiras raciais no Brasil isto é, das demarcaçóes fenotípicas, culturais e sociais - ocorreria devido à mestiçagem, que atuaria como uma mitigadora dessas diferenças.

Por outro lado, interpretaçóes posteriores reconheceram que o sistema de estratificação social poderia estar atrelado à cor da pele, mas também sugeriram que a influência da raça desapareceria com o tempo, não só através da miscigenação, mas também como uma decorrência natural da modernização e da industrialização. Nesse cenário, uma sociedade de classes se imporia gradativamente sobre a questão racial, como descreveram Cardo- 
so (2000, 2003), Cardoso e Ianni (1960) e Ianni (1962, 1987). Segundo essas interpretações, hierarquias sociais seriam baseadas explicitamente na classe, e implicitamente na raça. Fronteiras sociais seriam mais importantes do que categorias raciais, na definição de desigualdades. De acordo com essas referências, a consequente fluidez das fronteiras raciais e da própria groupness racial no país seria um produto da primazia da classe sobre a raça, como variável de classificação social.

Somente ao final dos anos de 1970, com o advento dos estudos quantitativos aplicados às ciências sociais no Brasil, a questão racial ganha saliência no debate sobre desigualdades sociais. Estudos, como o de Hasenbalg (2005), Hasenbalg e Silva (1988) e Silva (1978, 1979, 1980), constataram a relevância da discriminação racial na fabricação de fronteiras sociais pungentes, como as desigualdades raciais de oportunidades e recursos, para além de seus efeitos na produção de fronteiras simbólicas (preconceito racial, intolerância, entre outros).

Nossos resultados mostram que o padrão de fluidez das atitudes dos pardos converge com o das demais categorias raciais, e que o fator definidor das atitudes raciais dos brasileiros não é a raça, e sim a classe. Os estudos de Nogueira (1942) e Bicudo (1945), pioneiros na captação de atitudes e percepções sobre as atitudes raciais no Brasil, já haviam constatado que os preconceitos de cor e de classe ocupariam lugares próprios na sociedade brasileira dos anos de 1940 - o que, de certa forma, sugeriria que estas duas fronteiras, a racial e a social, seriam independentes. Seus estudos concluíram, ainda, que o preconceito de cor - que mais tarde seria chamado, por Nogueira (1998), de preconceito de marca - independeria do preconceito de classe, já que atingia também pessoas das chamadas "classes superiores". A ascensão social dos negros não implicava em maior assimilação pela classe média branca, evidenciando, assim, o viés da cor em nossa sociedade (Bicudo, 1945). É importante frisar, portanto, que nossos resultados não sugerem que a cor da pele seja uma variável irrelevante, mas demonstram que as opinióes e atitudes referentes às dimensóes captadas variam mais de acordo com a classe, do que segundo a cor da pele autodeclarada das pessoas entrevistadas (no- te-se, por exemplo, que a concordância com frases racistas, ilustrada na Figura 4 do anexo, varia mais entre, do que intra classes sociais). Além disso, chama atenção a fragilidade da subjetividade de grupo (e não só dos pardos) - o que caracteriza bem as tênues fronteiras simbólicas entre os grupos raciais no Brasil, fenômeno que já tem recebido atenção da literatura (Bailey, 2009; Lamont et al., 2016; Moraes Silva e Leão, 2012; Moraes Silva e Reis, 2015).

Isso não significa que não exista uma dimensão propriamente racial nas atitudes dos pardos, embora ela seja - em nossa linha de interpretação mais vinculada à lógica dos interesses, do que à da afirmação de identidade. Tanto as atitudes que retratam preconceito racial, como aquelas que se referem a políticas de cotas são ambas formadas em contextos sociais bem específicos. O racismo é um tipo de fenômeno que estimula o pardo a se diferenciar dos pretos e a se livrar da "sorte" comum. Ou seja, o pardo não tem nenhum incentivo para se sentir "negro", quando o que está em questão são os estereótipos e ofensas aos pretos. Nesse aspecto, pela sua condição de híbrido, os mulatos se integrariam mais facilmente aos brancos. O contrário é esperado quando seus interesses convergem com o dos pretos, como no caso da política de cotas. A flutuação atitudinal dos pardos parece assim advir, tal como evidenciado por Schwarztman (2009), não de uma motivação única e coesa - como a afirmação de uma identidade ou o cálculo racional para conseguir benefícios ${ }^{9}$-, mas sim de múltiplos "projetos raciais" e ideologias, que são adotados e combinados seletivamente para dar sentido a situaçóes específicas. Contextos distintos poderiam implicar, assim, mesmo na vida cotidiana, em variaçóes da rotulação racial, de acordo com a natureza e o propósito da interação.

Os aspectos cognitivos da variabilidade racial, quando apresentados como mecanismos explicativos da variabilidade racial, são denominados de 'esquemas raciais' (racial schemas) (Roth, 2012), que incluem 'associaçôes estereotípicas' (Frederickson, 2002, Saperstein e Penner, 2012) e a noção de 'elasticidade de cor' (Telles e Paschel, 2014), as quais sugerem que, em diferentes contextos, a cor da pele se traduz, de diferentes formas, em categorias ra- 
ciais. Quando se permite que as pessoas entrevistadas reflitam sobre suas escolhas raciais categóricas, por meio de entrevistas em profundidade, suas opinióes conflitantes tornam-se evidentes. E quando são motivadas a refletir sobre suas autopercepções raciais, resgatando, assim, suas trajetórias e memórias de eventos pertinentes, para em seguida traduzi-los em crenças que condicionam suas respostas, os paradoxos raciais marcados por opinióes conflitantes emergem. Uma das entrevistadas por Moraes Silva e Leão (2012), por exemplo, quando perguntada sobre o significado de ser parda, respondeu:

Uma mistura de morena com branca. Entendeu? Porque a cor, ela não é nem branca nem morena. Ela fica na meia estação. Por quê? Porque a parda te facilita. Você pode ficar branca, como eu 'to agora, e quando você for na praia pegar um bronze você fica moreninha. Essa é a facilidade da parda. [...] Mas eu graças a Deus eu nunca tive problema com relação à discriminação, desrespeito. Nada disso. [digitadora, 43 anos] (Moraes Silva e Leão, 2012, p. 129).

Este depoimento sugere, assim, ser plenamente possível que as pessoas, sobretudo pardas, manifestem suas identidades raciais, em função das possibilidades e oportunidades de cada contexto de socialização. Isso significa que as fronteiras simbólicas não reproduzem, necessariamente, as fronteiras sociais (Moraes Silva e Reis, 2015). Embora os pardos se situem próximos aos pretos, no que diz respeito às fronteiras sociais, eles redesenham, eventualmente, essas fronteiras no território simbólico e podem até se alinhar com os brancos, como no caso do preconceito racial. Ainda que, em nosso estudo, essa redefinição de fronteira no campo simbólico só tenha se revelado no caso do racismo, é possível que ela esteja captando um fenômeno mais amplo. Como observou Carlos Hasenbalg, em entrevista dada a Antônio Sérgio Guimarães, em 2006:

Cabe agregar que quando estudamos essas desigualdades, opondo brancos/não-brancos (pretos e pardos), nos referimos estritamente a processos de estratificação socioeconômica. Quando examinamos outras dimensôes da vida social envolvendo a sociabilidade dos indivíduos (por exemplo, o casamento e a amizade), esse padrão não se verifica, os pardos se diferenciando dos pretos e se aproximando mais dos brancos (Hasenbalg apud Guimarães, 2006, p. 263).

Temos também de considerar a natureza das variáveis que medem atitudes raciais, pois sabemos que princípios abstratos, tais como a ideia da mistura das raças, estimulam atitudes positivas (Sniderman, Brody e Tetlock, 1991). No caso brasileiro, isso é ainda mais reforçado, devido à ideologia da democracia racial que, mesmo não se concretizando plenamente no cotidiano, atua como princípio norteador do comportamento político (Bailey, 2009).

Atitudes que se referem a princípios abstratos como a mistura das raças -, ou a políticas que ainda não geraram consequências mais incisivas na (re) distribuição de recursos escassos - como a política de cotas -, tendem a endossar a tese de que a ausência de groupness racial é uma marca da sociedade brasileira. $\mathrm{O}$ que acentua ainda mais a complexidade da análise é a propensão a respostas socialmente desejáveis a perguntas que visam medir atitudes raciais - o que, naturalmente, aproxima os pontos de vista dos diferentes grupos raciais.

Ainda assim, em um contexto de forte identidade racial, esses fatores não seriam tão decisivos, pois prevaleceria a afirmação dos valores, crenças e visão do grupo racial. Esse é o caso dos Estados Unidos, onde as dramáticas fronteiras raciais não deixam espaço para ambiguidade. Nesse mundo sem regióes cinzentas, "pretos e brancos parecem ver o mundo de diferentes perspectivas; enquanto os brancos culpam os pretos por suas próprias desvantagens, os pretos culpam a discriminação" (Bailey, 2009, p. 311, tradução nossa).

\section{Consideraçóes finais}

Os resultados desse trabalho sinalizam que as atitudes dos pardos se alinham com a dos brancos, no que se refere ao racismo e ao princípio da mistura racial. Os pardos também se alinham aos pretos, em suas fronteiras sociais e nas suas opinióes 
sobre políticas de ação afirmativa. No entanto, a classe social da qual fazem parte aparece como um fator mais importante para induzir ao alinhamento de preferências, do que a cor autodeclarada. Isso é constatado, ao notarmos que a opiniáo sobre o apoio às cotas varia mais por classe, do que por cor da pele. Para uma mesma classe social, as opinióes de brancos, pardos e pretos sobre as cotas raciais são muito parecidas, alinhando-se, assim, aos resultados encontrados anteriormente, a partir de outros bancos de dados nacionalmente representativos (Bailey, 2004, 2009; Bailey, Fialho e Peria, 2015).

Uma vez que tanto a maioria dos brancos, quanto a dos pardos e pretos apoiam as cotas raciais, concluímos, ainda, que não há evidência para a ideologia sugerida por Bonilla-Silva (2013), de que o Brasil seria 'daltônico ao racismo' (color-blind racism). Se este fosse o caso, o percentual de apoio dos brancos às cotas raciais seria bem menor do que aquele dos pretos, tal como constatado pelo autor, no caso americano. Como explicação alternativa, sugerimos, assim como Bailey, Fialho e Peria (2015, p. 26), que o apoio racial consensual às cotas seja um reflexo da crescente conscientizaçáo em relaçâo ao racismo. Uma vez que a maioria reconhece a presença de desvantagens estruturais raciais, ela passa igualmente a apoiar as açóes afirmativas.

Nosso trabalho aponta a fragilidade da subjetividade de grupo racial no Brasil. Isso porque, além da tendência à convergência atitudinal entre os grupos raciais, a classe é a principal preditora das atitudes raciais dos brasileiros, aqui consideradas. Nossos resultados se contrapóem ao "senso comum popular" de inexistência de clivagens ideológicas, justamente por mostrar que tais clivagens acontecem entre os grupos raciais, em duas das três fronteiras simbólicas analisadas: pardos e pretos possuem níveis distintos de concordância com frases de cunho racista, e pardos são marginalmente mais propensos a dar alto apoio às cotas raciais, do que brancos (vide Figura 1). Esses resultados são sociologicamente relevantes e fornecem, também, uma perspectiva crítico-acadêmica, ao mapear e quantificar a permeabilidade de certas fronteiras simbólicas, vulgarmente entendidas como racialmente sobrepostas. Das 18 possibilidades consideradas (6 dimensóes para cada uma das três fronteiras simbólicas em questão), há forte sobreposição em 12 delas. Para as outras seis (pardos versus pretos, na fronteira simbólica 1, e brancos versus pardos, na fronteira simbólica 3), tal sobreposição não é evidente.

Contudo, os resultados apresentados devem ser interpretados com cautela, não apenas devido à natureza das atitudes examinadas e ao contexto em que se inserem, mas também em função de os pardos apresentarem atitudes tão racistas quanto os brancos - o que deixa aberta a possibilidade de que novos estudos revelem padróes atitudinais diferentes dos que encontramos aqui.

É claro, também, que o tipo de análise que apresentamos aqui não cobre a dimensão propriamente comportamental. Não chega a ser surpresa o fato de os pretos, no Brasil, relatarem sofrer discriminação racial (36\%) com maior frequência do que os pardos (18\%) (Bailey, 2009; Moraes Silva e Reis, 2015). Além disso, "[p] esquisas de opinião e entrevistas demonstram que os pardos muitas vezes não são vistos como um grupo discriminado" (Almeida, Schroeder e Cheibub, 2002; Schwartzman, 2009), ou que "apresentam índices de percepção da discriminação significativamente mais baixos do que os indivíduos que se autoclassificam como pretos" (Datafolha, 1995, 2008; DataUFF, 2002; Fundação Perseu Abramo, 2003; Rennó et al., 2011) (apud Daflon et al., 2017, pp. 293-294). Entretanto, sem dados longitudinais, é impossível dizer se a percepção da discriminação induz ao "empardecimento", ou se os pardos, uma vez assumidos como pertencentes a fronteiras raciais estáveis, vivenciam, de fato, processos discriminatórios com menor intensidade.

Por fim, em relação à política de cotas raciais, é possível que as recentes políticas públicas direcionadas a grupos raciais tenham um efeito, a médio prazo, sobre a constituição de grupos raciais mais coesos no Brasil, aproximando pardos e pretos, e isolando os brancos. É também possível que, ao contrário, as linhas de cor sejam redesenhadas e os pardos sejam excluídos da "negritude". ${ }^{10}$ Porém, essas análises só poderão ser feitas no futuro, a partir da disponibilidade de séries temporais mais extensas. 


\section{Notas}

1 Pesquisas realizadas pelo Datafolha: http://media. folha.uol.com.br/datafolha/2016/03/21/manifestacao-18-03-2016.pdf e http://media.folha.uol.com.br/ datafolha/2016/03/14/manifestacao_13_03_2016.pdf

2 Entre 1840 e 1860, a categoria "mulatto" constou no censo americano, mas o termo não foi definido aos entrevistadores. Nas duas décadas seguintes, definiu-se oficialmente "mulattoes" como "todas as pessoas que possuíssem algum traço perceptível de sangue africano". Em 1890, o censo instruiu os enumeradores a registrarem a proporção exata de "sangue africano", confiando, mais uma vez, apenas na visibilidade. Em 1900, a instrução foi para que pure Negroes fossem contados separadamente dos mulatos, definidos como "pessoas com algum resquício de sangue preto". Em 1920, retirou-se a categoria mulatto do censo, passando a adotar-se, até os dias de hoje, a opção "preto" (black) para fazer referência a qualquer pessoa com alguma ancestralidade preta/ negra (black) (Davis, 2001, pp. 11-12). Esse procedimento ficou conhecido como one-drop rule. Ser classificado como "mulato", entre 1870 e 1920, relacionava-se, portanto, ao modo como as pessoas eram percebidas pelo enumerador, e não em funçáo de uma medida direta da sua suposta ancestralidade, e nem de como os entrevistados se autoidentificavam. Nesse realinhamento das relaçóes raciais, os brancos perderam a sua aliança com os mulatos livres e, também, as vantagens de haver um grupo de amortecimento (buffer group) entre eles e os pretos náo misturados. Nas palavras de Davis (2001, p. 42), tal "realinhamento iniciou uma mudança no senso de identidade do mulato, especialmente dos mais claros, que começaram a se ver como negros, ao invés de como um grupo marginalizado de "quase brancos'" (tradução nossa). Essa descrição ilustra o caráter histórico, mutável e social de raça nos Estados Unidos, mesmo que, hoje, cerca um terço das pessoas do país ainda a considere como um atributo biológico (Rockett, 2018).

3 Consideraremos 2644 casos válidos na análise estatística.

4 Optamos por utilizar uma combinação de variáveis através da média, ao invés de análise fatorial ou de componentes principais, por duas razóes. Primeiro, porque estas técnicas de redução de variabilidade não são, em geral, indicadas para variáveis categóricas, como é o nosso caso. Análises fatoriais assumem que as variáveis são contínuas e normalmente distribuídas. Em segundo lugar, optamos por empregar a média, porque mesmo quando utilizamos técnicas adequadas para a redu- ção de variabilidade de variáveis categóricas (polychoric estimates), constatamos alta correlação entre os fatores gerados e a medida construída a partir da média aritmética. O coeficiente de determinação (R2) entre nossas variáveis e o seu primeiro fator dominante são: 0,79 na fronteira simbólica 1; 0,77 na fronteira simbólica 2; e 0,92 na fronteira simbólica 3. Estes resultados indicam que, tecnicamente, optar pela média ou por polychoric estimates nos conduziria a resultados semelhantes.

5 O Critério Brasil atribui pontos específicos à presença dos citados itens no domicílio, os quais, somados, indicam uma classe de pertença segundo os cortes abaixo:

\begin{tabular}{ll}
\hline Classe & Pontos \\
\hline A1 & $42-46$ \\
\hline A2 & $35-41$ \\
\hline B1 & $29-34$ \\
\hline B2 & $23-28$ \\
\hline C1 & $18-22$ \\
\hline C2 & $14-17$ \\
\hline D & $8-13$ \\
\hline E & $0-7$ \\
\hline
\end{tabular}

A variável "Critério Brasil", disponível no banco de dados da Pesquisa Racismo Cordial 2008 do Datafolha, baseia-se na questáo P.69 do questionário, e tem média 18,59 com desvio-padrão igual a 6,85.

6 As três frases que compóem a fronteira simbólica 1 foram teoricamente selecionadas por: (a) serem essencialmente e inequivocamente racistas; mas (b), ao mesmo tempo, fazerem parte do imaginário simbólico, ao representarem infames ditos populares. Assumimos que estas duas características confeririam maior variabilidade à escala construída, mesmo tratando-se de um comportamento socialmente indesejável. E, de fato, o diferencial entre as probabilidades preditas na Figura 4 mostra que tal variabilidade foi alcançada, tanto por raça quanto por classe.

7 As perguntas utilizadas para captar a concordância com frases de cunho racista são claramente incapazes de contornar o viés do politicamente indesejável e "aferir racismo". Somente as pessoas declaradamente racistas concordariam com as frases apresentadas aos entrevistados. Medir a discriminação, no entanto, não é o propósito deste artigo. Nosso interesse está em medir a diferença de opinióes entre brancos e pardos, e entre pardos 
e pretos, com relação às frases apresentadas; por isso, a qualidade das perguntas é menos importante do que a semelhança entre as concordâncias raciais encontradas. Todos os grupos discordam fortemente das frases apresentadas, mas, em média, a proporção de pardos que discorda é mais parecida com a de brancos, do que com a proporção de pretos. Esse é o resultado-chave da análise referente à fronteira simbólica 1 .

8 As razóes de chance das regressóes categóricas ordinais, assim como os gráficos derivados por raça e classe para as demais fronteiras, simbólicas e sociais, encontram-se em anexo.

9 Há evidência sugerindo que a raça percebida possa ser manipulada para tirar vantagem de situaçóes econômicas e sociais. Francis e Tannuri-Pianto (2012, 2013) e Francis-Tan e Tannuri-Pianto (2015), por exemplo, mostram que a adoção de políticas de ação afirmativa na Universidade de Brasília provocou um aumento do número de pessoas que se reportaram como negras. Processo similar também ocorreu nos Estados Unidos (Antman e Duncan, 2015) e na Índia (Cassan, 2015), em resposta a políticas de distribuição de terras específicas por casta.

10 Agradecemos a um dos revisores do artigo por levantar esta alternativa.

\section{BIBLIOGRAFIA}

ALMEIDA, Alberto Carlos; SCHROEDER, Andréia \& CHEIBUB, Zairo (orgs.). (2002), PESB: Pesquisa social brasileira, Sáo Paulo, Consórcio de Informações Sociais.

ANTMAN, Francisca \& DUNCAN, Brian. (2015), "Incentives to identify: racial identity in the age of affirmative action". The Review of Economics and Statistics, 97 (3): 710-713.

ASSOCIAÇÃO Brasileira de Empresas de Pesquisa. (2010), Dados com base no Levantamento Sócio Econômico 2008 - Ibope. Disponível em: <http://www.abep.org/criterio-brasil>, consultado em 15/9/2018.

AVRITZER, Leonardo \& GOMES, Lilian Cristina Bernardo. (2013), "Política de reconhecimento, raça e democracia no Brasil". Dados, 56 (1): 39-68.

BAILEY, Stanley R. (2004), "Group dominance and the myth of racial democracy: antiracist attitudes in Brazil". American Sociological Review, 69 (5): 728-747.

BAILEY, Stanley R. (2008), "Unmixing for race making in Brazil". American Journal of Sociology, 114 (3): 577-614.

BAILEY, Stanley R. (2009), Legacies of race: identities, attitudes and politics in Brazil, Stanford, Stanford University Press.

BAILEY, Stanley R. \& TELLES, Edward E. (2006), "Multiracial versus collective black categories: examining census classification debates in Brazil". Ethnicities, 6 (1): 74-101.

BAILEY, Stanley. R.; FIALHO, Fabrício. M. \& PENNER, Andrew. M. (2015), "Interrogating race: color, racial categories and class across the Americas". American Behavioral Scientist, 1-18.

BAILEY, Stanley R.; FIALHO, Fabrício \& PERIA, Michelle. (2015), "Support for race-targeted affirmative action in Brazil". Ethnicities, 0 (0): 1-34.

BONILLA-SILVA, Eduardo. (2013), Racism without Racists. Lanham, MD, Rowman \& Littlefield.

BRANT, Rollin. (1990), "Assessing proportionality in the proportional odds model for ordinal logistic regression". Biometrics, 46: 1171-1178.

BRUBAKER, Rogers. (2002), "Ethnicity without groups". European Journal of Sociology/Archives Européennes de Sociologie, 43 (2): 163-189.

BRUBAKER, Rogers. (2009), "Ethnicity, race and nationalism". Annual Review of Sociology, 35: 21-42.

BRUBAKER, Rogers \& COOPER, Frederick. (2000), "Beyond 'identity". Theory and Society, 29 (1): 1-47.

BUENO, Natália Salgado \& (2010), Raça e comportamento político em perspectiva comparadaevidências de Belo Horizonte e Cidade do Cabo. Dissertaçáo de Mestrado. Universidade de São Paulo, São Paulo.

BUENO, Natália Salgado; FIALHO, Fabrício Mendes. (2009), "Race, resources and political participation in a Brazilian city". Latin American Research Review, 44 (2): 59-83.

CAMPBELL, Donald T. (1958), "Common fate, similarity, and other indices of the status of aggregates of persons as social entities". Behavioral Science, 3: 14-25. 
CARDOSO, Fernando Henrique. (2000), Negros em Florianópolis: relaçóes sociais e econômicas. Florianópolis, Insular.

CARDOSO, Fernando Henrique. (2003), Capitalismo e escravidão no Brasil meridional: o negro na sociedade escravocrata do Rio Grande do Sul. Rio de Janeiro, Civilização Brasileira.

CARDOSO, Fernando Henrique \& IANNI, Octavio. (1960), Cor e mobilidade social em Florianópolis: aspectos das relaçóes entre negros $e$ brancos numa comunidade do Brasil meridional. São Paulo, Companhia Editora Nacional.

CASSAN, Guilhem. (2015), "Identity-based policies and identity manipulation: evidence from colonial Punjab." American Economic Journal: Economic Policy 7 (4): 103-31.

DAFLON, Verônica Toste. (2014), Tão longe, tão perto: pretos e pardos e o enigma racial brasileiro. Tese de Doutorado. Instituto de Estudos Sociais e Políticos, Rio de Janeiro.

DAFLON, Verônica Toste; CARVALHAES, Flavio \& FERES JÚNIOR, João. (2017), “Sentindo na pele: percepções da discriminação cotidiana de pretos e pardos no Brasil”. Dados: Revista de Ciências Sociais, 60 (2): 293-330.

DANIEL, Reginald. (2006), Race and multiraciality in Brazil and the United States: converging paths? Filadélfia, Pennsylvania State University Press.

DATAFOLHA, Instituto de Pesquisas. (1995), "Racismo Cordial”. São Paulo, Consórcio de Informaçóes Sociais.

DATAFOLHA, Instituto de Pesquisas. (2012), "Racismo Cordial” (2008), Banco de dados, São Paulo, Consórcio de Informaçôes Sociais. Disponível em: www.cis.org.br, consultado em 22/09/2015.

DATAUfF. (2002), PESB - Pesquisa Social Brasileira. Niterói, Datauff.

DAVIS, F. James. (2001), Who is black? One nation's definition, Tenth anniversary edition, Pensilvânia, The Pennsylvania State University Press.

DEGLER, Carl Neumann. (1971), Neither black nor white: slavery and race relations in Brazil and the United States. Nova York, Macmillan Publishing Company.

FERNANDES, Florestan. (1965), A Integração do Negro na Sociedade de Classes. São Paulo, Companhia Editora Nacional.
FERNANDES, Florestan. (2007), O negro no mundo dos brancos. São Paulo, Global.

FUNDAÇÃO PERSEU ABRAMO. (2003), Discriminação racial e preconceito de cor no Brasil, São Paulo, Fundação Perseu Abramo.

FRANCIS, Andrew M. \& TANNURI-PIANTO, Maria Eduarda (2012), "Using Brazil's racial continuum to examine the short-term effects of affirmative action in higher Education". Journal of Human Resources, 47 (3): 754-784.

FRANCIS, A. M. \& TANNURI-PIANTO, M. (2013) "Endogenous race in Brazil: affirmative action and the construction of racial identity among young adults". Economic Development and Cultural Change 61 (4): 731-753.

FRANCIS-TAN, Andrew \& TANNURI-PIANTO, Maria. (2015), "Inside the black box: affirmative action and the social construction of race in Brazil". Ethnic and Racial Studies, 38 (15): 2771-2790.

FREDERICKSON, George M. (2002), Racism: a short history. Princeton, N.J., Princeton University Press.

FREYRE, Gilberto. (1973), Casa-Grande e Senzala. Rio de Janeiro, José Olympio.

GUIMARÁES, Antônio Sérgio Alfredo. (2003), "Como trabalhar com 'raça' em sociologia". Educação e Pesquisa, 19 (1): 93-107.

GUIMARÃES, Antônio Sérgio Alfredo. (2006), "Entrevista com Carlos Hasenbalg". Tempo Social, 18 (2): 259-268.

GUIMARÁES, Antônio Sérgio Alfredo. (2009), Racismo e antirracismo no Brasil. 1 ed., São Paulo, Editora 34.

HARRIS, Marvin. (1964), Patterns of race in the Americas. Nova York, Walker and Company.

HASENBALG, Carlos. (2005), Discriminação e desigualdades raciais no Brasil. 2 ed., Belo Horizonte/ Rio de Janeiro, Editora UFMG/Iuperj.

HASENBALG, Carlos \& SILVA, Nelson do Valle (orgs.). (1988), Estrutura social, mobilidade e raça. Rio de Janeiro, Iuperj/Vértice.

HOLANDA, Sérgio Buarque de. (1995), Raizes do Brasil. 26 ed., São Paulo, Companhia das Letras.

IACUS, Stefano M.; KING, Gary \& PORRO, Giuseppe. (2012), "Causal inference without 
balance checking: coarsened exact matching". Political Analysis, 20 (1): 1-24.

IANNI, Octavio. (1962), As metamorfoses do escravo. São Paulo, Difusão Europeia do Livro.

IANNI, Octavio. (1987), Raças e classes sociais no Brasil. 3 ed., São Paulo, Brasiliense.

JUNN, Jane; MENDELBERG, Tali \& CZAJA, Erica. (2012), "Race and the group bases of public opinion", in A. Berinsky (org.). New directions in Public Opinion, Nova York, Routledge.

KINDER, Donald \& SANDERS, Lynn. (1996), Divided by color: racial politics and democratic ideals. Chicago, University of Chicago Press.

KING, Gary; TOMZ, Michael \& WITTENBERG, Jason. (2000), "Making the most of statistical analyses: improving interpretation and presentation". American Journal of Political Science, 44 (2): 347-361.

LAMONT, Michele \& MOLNÁR, Virag. (2002), "The study of boundaries in the social sciences". Annual Review of Sociology, 28: 167-195.

LAMONT, Michèle; MORAES SILVA, Graziela; WELBURN, Jessica; GUETZKOW, Joshua; MIZRACHI, Nissim; HERZOG, Hanna \& REIS, Elisa. (2016), Getting respect: responding to stigma and discrimination in the United States, Brazil and Israel. Princeton, Princeton University Press.

LIEBLER, C. A.; PORTER, S. R.; FERNANDEZ, L. E.; NOON, J. M. \& ENNIS, S. R. (2017), "America's churning races: race and ethnicity response changes between Census 2000 and the 2010 Census". Demography, 54 (1): 259-284.

LONG, Scott \& FREESE, Jeremy. (2006), Regression models for categorical dependent variables using Stata. 2 ed., Texas - College Station, Stata Press Corporation.

LOVEMAN, Mara. (1999), "Making 'race' and nation in the United States, South Africa and Brazil: taking 'making' seriously". Theory and Society, 28 (6): 903-927.

MARTELETO, Leticia J. (2012). “Educational inequality by race in Brazil, 1982-2007: structural changes and shifts in racial classification". Demography, 49 (1): 337-58.

MCCULLAGH, Peter. (1980), "Regression models for ordinal data". Journal of Royal Statistics Society, 42 (2): 109-142.
MIRANDA, Victor. (2014), Measuring racial self-identification over the life course in Brazil, 19402013, Filadélfia, University of Pennsylvania. Disponível em: <https://repository.upenn.edu/ dissertations/AAI3623640>, consultado em 22/09/2018.

MORAES SILVA, Graziella. (2015), "After racial democracy: contemporary puzzles in race relations in Brazil, Latin America and beyond from a boundaries perspective". Current Sociology: 64 (5): 794-812.

MORAES SILVA, Graziella \& LEÃO, Luciana T. de Souza. (2012), "O paradoxo da mistura: identidades, desigualdades e percepção de discriminação entre brasileiros pardos”. Revista Brasileira de Ciências Sociais, 27 (80): 117-133. MORAES SILVA, Graziella \& REIS, Elisa P. (2015), "Interpretaçóes e reaçóes à estigmatização étnico-racial: narrativas dos negros brasileiros em perspectiva comparada”. Interseçôes: Revista de estudos interdisciplinares, 17 (2): 327-349.

MUNIZ, Jeronimo Oliveira. (2012), "Preto no branco? Mensuração, relevância e concordância classificatória no país da incerteza racial”. Dados, 55 (1): 251-282.

MUNIZ, Jeronimo Oliveira. (2016), "Inconsistências e consequências da variável raça para a mensuração de desigualdades". Civitas, 16 (2): 62-86.

OMI, Michael; WINANT, Howard. (1994), Racial formation in the United States: from the 1960s to the 1990s. Nova York, Routledge.

PETERSEN, William. (1987), "Politics and the measurement of ethnicity", in: P. Starr e W. Alonso, The politics of numbers. Nova York, Russell Sage.

PIERSON, Donald. (1945), Brancos e pretos na Bahia: estudo de contato racial. São Paulo, Companhia Editora Nacional.

PORTO, Nathália França Figueredo. (2016), Comunidades raciais no Brasil: uma análise dos efeitos de raça e classe nas atitudes raciais brasileiras. Dissertação de Mestrado. Universidade Federal de Minas Gerais, Belo Horizonte.

POWERS, Daniel A.; XIE, Yu. (2008), Statistical methods for categorical data analysis. 2. ed., San Diego, Emerald Group Publishing. 
RENNÓ, Lucio R. et al. (2011), Legitimidade e qualidade da democracia no Brasil: uma visáo da cidadania. São Paulo/Nashville, Intermeios/ Lapop.

ROCKETT, Darcel. (2018), "Skin color vs. identity: how Americans view race 'a huge surprise”. Chicago Tribune, 17 de setembro. Disponível em: <https://www.chicagotribune.com/lifestyles/sc-fam-race-genetics-study-0925-story. html>. Consultado em 24/1/2019.

ROTH, Wendy D. (2012), Race migrations: latinos and the cultural transformation of race. Stanford, Califórnia, Stanford University Press.

SANSONE, Lívio. (1996), "Nem somente preto ou negro: o sistema de classificação racial no Brasil que muda". Afro-Ásia, 18: 165-187.

SAPERSTEIN, Aliya \& PENNER, Andrew M. (2012), "Racial fluidity and inequality in the United States." American Journal of Sociology, 118 (3): 676-627.

SAPERSTEIN, Aliya \& GULLICKSON, Aaron. (2013), “A 'Mulatto Escape Hatch' in the United States? Examining evidence of racial and social mobility during the Jim Crow era." Demography, 50 (5): 1921-1942.

SCHWARTZMAN, Luiza Farah. (2009), "Seeing like citizens: unofficial understandings of official racial categories in a Brazilian university". Journal of Latin American Studies, 41 (2): 221-250.

SCHWARCZ, Lilia Moritz \& STARLING, Heloisa Maria Murgel. (2015), Brasil: uma biografia. São Paulo, Companhia das Letras.

SENKEVICS, Adriano Souza. (2017), "De brancos para negros? Uma análise longitudinal da reclassificação racial no Enem 2010-2014”. Trabalho apresentado na 38a. Reunião Nacional da Anped, 1-5 de out., São Luís, MA.

SILVA, Nelson do Valle. (1978), Black-white income differentials in Brazil. Ann Arbor, University of Michigan Press.

SILVA, Nelson do Valle. (1979), "As duas faces da mobilidade". Dados, 21: 49-67.

SILVA, Nelson do Valle. (1980), "O preço da cor: diferenciais raciais na distribuição de renda no Brasil”. Pesquisa e planejamento econômico, 10 (1): 21-44.
SILVEIRA, Leonardo; MUNIZ, Jerônimo \& TELLES, Edward. (2018), "Fluidez racial e reclassificação no Brasil". Trabalho apresentado no 42\%. Encontro Anual da Anpocs, 22-26 de out., Caxambu, MG.

SKIDMORE, Thomas E. (1993), Black into white: race and nationality in Brazilian thought. Durham, Duke University Press.

SNIDERMAN, Paul; BRODY, Richard \& TETLOCK, Philip. (1991), Reasoning and choice: explorations in political psychology. Nova York, Cambridge University Press.

STATACORP. (2017), Stata Base Reference Manual, release 15. Texas, Stata Press, College Station, StataCorp LLC.

TELLES, Edward E. (2003), Racismo à brasileira: uma nova perspectiva sociológica. Rio de Janeiro, Relume Dumará.

TELLES, Edward; PASCHEL, Tianna. (2014), "Who is black, white, or mixed race? How skin color, status, and nation shape racial classification in Latin America". American Journal of Sociology, 120 (3): 864-907.

WAGLEY, Charles (org.). (1952), Race and class in rural Brazil. Paris, Unesco. 


\section{Anexos}

\section{Tabela 4}

\section{Regressão Ordinal para a Chance de Pertencer a Classe Social Baixa, Média ou Alta}

\section{Covariáveis}

Cor autodeclarada(ref.Pardos):

\begin{tabular}{ll}
\hline \multicolumn{1}{c}{1 se branco } & $1,3824^{* * *}$ \\
\hline 1 se preto & 0,9106 \\
\hline 1 se homem & $1,3780^{* * *}$ \\
\hline Idade & $0,9755^{* * *}$ \\
\hline Regiáo & 1,0158 \\
\hline$\quad$ Sul & $0,4593^{* * *}$ \\
\hline$\quad$ Nordeste & 0,962 \\
\hline$\quad$ Norte/ Centro-oeste & $0,2304^{* * *}$ \\
\hline Ponto de corte 1 (classe baixa) & $2,5805^{* * *}$ \\
\hline Ponto de corte 2 (classe média) & 2644 \\
\hline $\mathrm{N} \quad$ & 0,042 \\
\hline Pseudo-R2 & -2500 \\
\hline Log-likelihood & 5100 \\
\hline AIC & \\
\hline${ }^{*} \mathrm{p}<0,05 ;{ }^{* *} \mathrm{p}<0,01 ;{ }^{* * *} \mathrm{p}<0,001$ & \\
\hline
\end{tabular}

Fonte: Elaboração própria, com base em Datafolha (2008). 
Tabela 5

\section{Regressão Ordinal para a Concordância com Frases Racistas}

\begin{tabular}{|c|c|c|c|}
\hline Covariáveis & modelo1 & modelo2 & modelo3 \\
\hline \multicolumn{4}{|l|}{ Cor autodeclarada (ref. Pardos): } \\
\hline 1 se branco & 0,9941 & 0,9202 & 0,7757 \\
\hline 1 se preto & $1,4696^{* *}$ & $1,5281^{* *}$ & 1,3936 \\
\hline 1 se homem & 0,8912 & $0,8214^{*}$ & $0,8262^{*}$ \\
\hline Idade & $0,9726^{* * *}$ & $0,9773^{* * *}$ & $0,9773^{* * *}$ \\
\hline \multicolumn{4}{|l|}{ Região } \\
\hline Sul & $1,4349^{* *}$ & $1,4367^{* *}$ & $1,4329^{* *}$ \\
\hline Nordeste & $0,6774^{* * *}$ & $0,8046^{*}$ & $0,8068^{*}$ \\
\hline Norte/ Centro-oeste & 0,9844 & 0,9891 & 0,9939 \\
\hline \multicolumn{4}{|l|}{ Classe social (ref. Baixa): } \\
\hline Média & & $1,9596^{* * *}$ & $1,7366^{* * *}$ \\
\hline Alta & & $4,6487^{* * *}$ & $3,5190^{* * *}$ \\
\hline \multicolumn{4}{|l|}{ Interações: } \\
\hline Brancos de classe média & & & 1,2877 \\
\hline Brancos de classe alta & & & 1,7421 \\
\hline Pretos de classe média & & & 1,1873 \\
\hline Pretos de classe alta & & & 1,2026 \\
\hline Ponto de corte 1 (classe baixa) & $0,0164^{* * *}$ & $0,0304^{* * *}$ & $0,0282^{* * *}$ \\
\hline Ponto de corte 2 (classe média) & $0,1548^{* * *}$ & $0,3058^{* * *}$ & $0,2845^{* * *}$ \\
\hline $\mathrm{N}$ & 2644 & 2644 & 2644 \\
\hline Pseudo-R2 & 0,038 & 0,068 & 0,069 \\
\hline Log-likelihood & -2000 & -1900 & -1900 \\
\hline AIC & 4000 & 3800 & 3900 \\
\hline${ }^{*} \mathrm{p}<0,05 ;{ }^{* *} \mathrm{p}<0,01 ;{ }^{* * *} \mathrm{p}<0,001$ & & & \\
\hline
\end{tabular}

Fonte: Elaboração própria, com base em Datafolha (2008). 
Tabela 6

Regressão Ordinal para a Concordância sobre a Desejabilidade da Mistura Racial

\begin{tabular}{|c|c|c|c|}
\hline Covariáveis & modelo4 & modelo5 & modelo6 \\
\hline \multicolumn{4}{|l|}{ Cor autodeclarada(ref.Pardos): } \\
\hline 1 se branco & 1,0435 & 1,0923 & 1,2903 \\
\hline 1 se preto & 0,9908 & 0,9806 & 1,0776 \\
\hline 1 se homem & 1,0641 & 1,1076 & 1,1049 \\
\hline Idade & $1,0067^{*}$ & 1,0037 & 1,0037 \\
\hline \multicolumn{4}{|l|}{ Região } \\
\hline Sul & 0,8482 & 0,8498 & 0,8530 \\
\hline Nordeste & 1,0723 & 0,9732 & 0,9692 \\
\hline Norte/ Centro-oeste & 0,8346 & 0,8291 & 0,8236 \\
\hline \multicolumn{4}{|l|}{ Classe social (ref. Baixa): } \\
\hline Média & & $0,7120^{* *}$ & 0,8318 \\
\hline Alta & & $0,4169^{* * *}$ & $0,4396^{* *}$ \\
\hline \multicolumn{4}{|l|}{ Interaçóes: } \\
\hline Brancos de classe média & & & 0,7289 \\
\hline Brancos de classe alta & & & 0,8553 \\
\hline Pretos de classe média & & & 0,8091 \\
\hline Pretos de classe alta & & & 1,0581 \\
\hline Ponto de corte 1 (classe baixa) & $5,0573^{* * *}$ & $3,4676^{* * *}$ & $3,7413^{* * *}$ \\
\hline Ponto de corte 2 (classe média) & $118,6752^{* * *}$ & $82,4334^{* * *}$ & $89,0555^{* * *}$ \\
\hline $\mathrm{N}$ & 2644 & 2644 & 2644 \\
\hline Pseudo-R2 & 0,0033 & 0,0136 & 0,0144 \\
\hline Log-likelihood & -1500 & -1400 & -1400 \\
\hline AIC & 2900 & 2900 & 2900 \\
\hline${ }^{*} \mathrm{p}<0,05 ;^{* *} \mathrm{p}<0,01 ;{ }^{* * *} \mathrm{p}<0,001$ & & & \\
\hline
\end{tabular}

Fonte: Elaboração própria, com base em Datafolha (2008). 
Tabela 7

\section{Regressão Ordinal para a Concordância com as Cotas Raciais}

\begin{tabular}{|c|c|c|c|}
\hline Covariáveis & modelo7 & modelo8 & modelo9 \\
\hline \multicolumn{4}{|l|}{ Cor autodeclarada (ref. Pardos): } \\
\hline 1 se branco & $0,8456^{*}$ & 0,9196 & 0,9038 \\
\hline 1 se preto & 1,0766 & 1,0713 & 1,2278 \\
\hline 1 se homem & $0,8659^{*}$ & 0,9258 & 0,9254 \\
\hline Idade & $1,0061^{* *}$ & 1,0010 & 1,0010 \\
\hline \multicolumn{4}{|l|}{ Região (ref. Sudeste): } \\
\hline Sul & 1,1261 & 1,1527 & 1,1564 \\
\hline Nordeste & $1,5588^{* * *}$ & $1,3368^{* *}$ & $1,3346^{* *}$ \\
\hline Norte/ Centro-oeste & 0,9137 & 0,9067 & 0,9071 \\
\hline \multicolumn{4}{|l|}{ Classe social (ref. Baixa): } \\
\hline Média & & $0,5421^{* * *}$ & $0,5761^{* * *}$ \\
\hline Alta & & $0,2289^{* * *}$ & $0,2037^{* * *}$ \\
\hline \multicolumn{4}{|l|}{ Interações: } \\
\hline Brancos de classe média & & & 0,9622 \\
\hline Brancos de classe alta & & & 1,2596 \\
\hline Pretos de classe média & & & 0,7537 \\
\hline Pretos de classe alta & & & 1,0429 \\
\hline Ponto de corte 1 (classe baixa) & $0,3956^{* * *}$ & $0,1893^{* * *}$ & $0,1921^{* * *}$ \\
\hline Ponto de corte 2 (classe média) & $1,4370^{* *}$ & $0,7364^{*}$ & 0,7479 \\
\hline $\mathrm{N}$ & 2644 & 2644 & 2644 \\
\hline Pseudo-R2 & 0,0086 & 0,0378 & 0,0383 \\
\hline Log-likelihood & -2.800 & -2.700 & -2.700 \\
\hline AIC & 5.600 & 5.400 & 5.400 \\
\hline${ }^{*} \mathrm{p}<0,05 ;{ }^{* *} \mathrm{p}<0,01 ;{ }^{* * *} \mathrm{p}<0,001$ & & & \\
\hline
\end{tabular}

Fonte: Elaboração própria, com base em Datafolha (2008). 
Figura 3

Probabilidades Preditas de Pertencimento a Classes Sociais por Raça

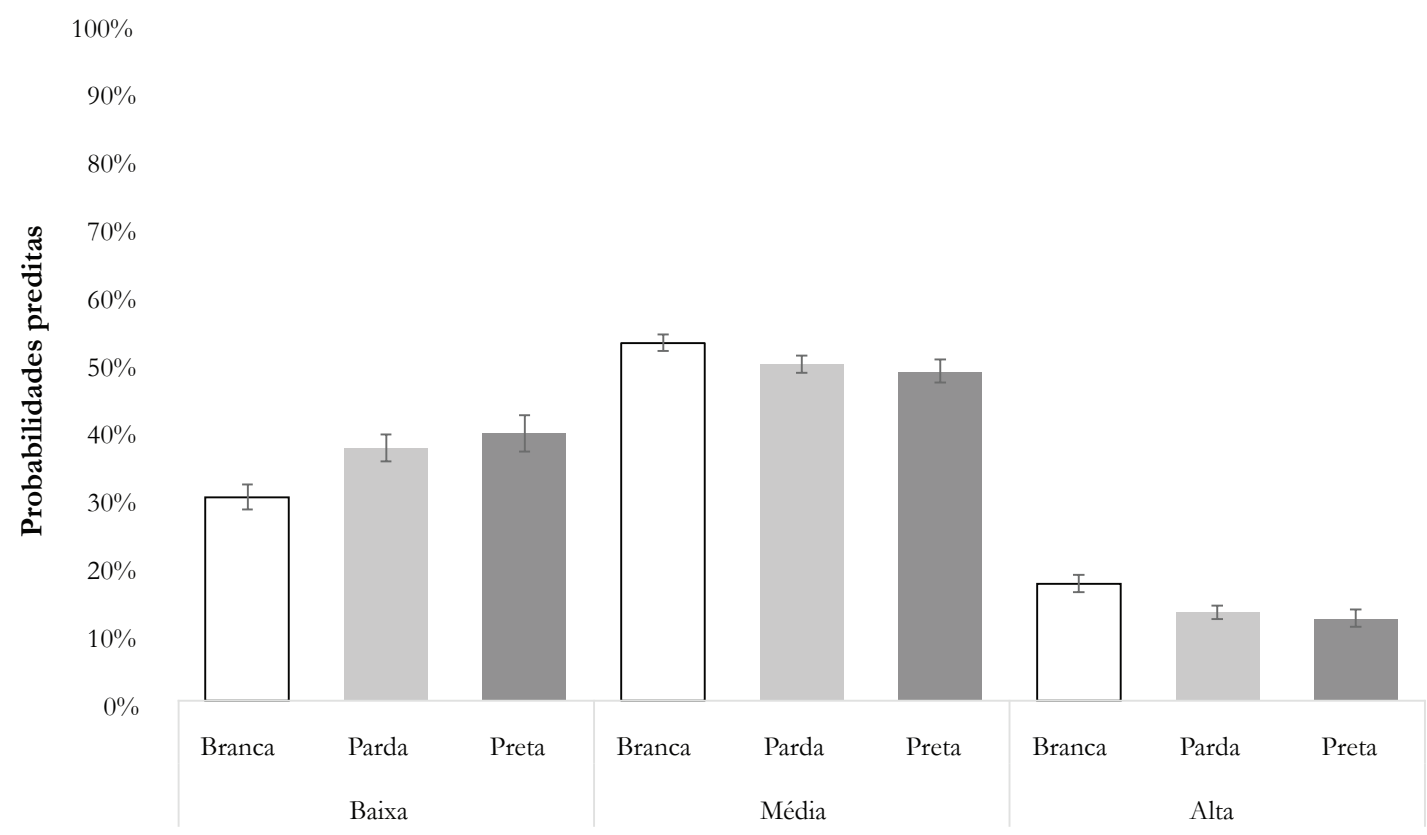

Classes sociais

Fonte: Elaboração própria, com base em Datafolha (2008). 
Figura 4

Probabilidades Preditas de Concordância com Frases Racistas, por Raça e Classe Social

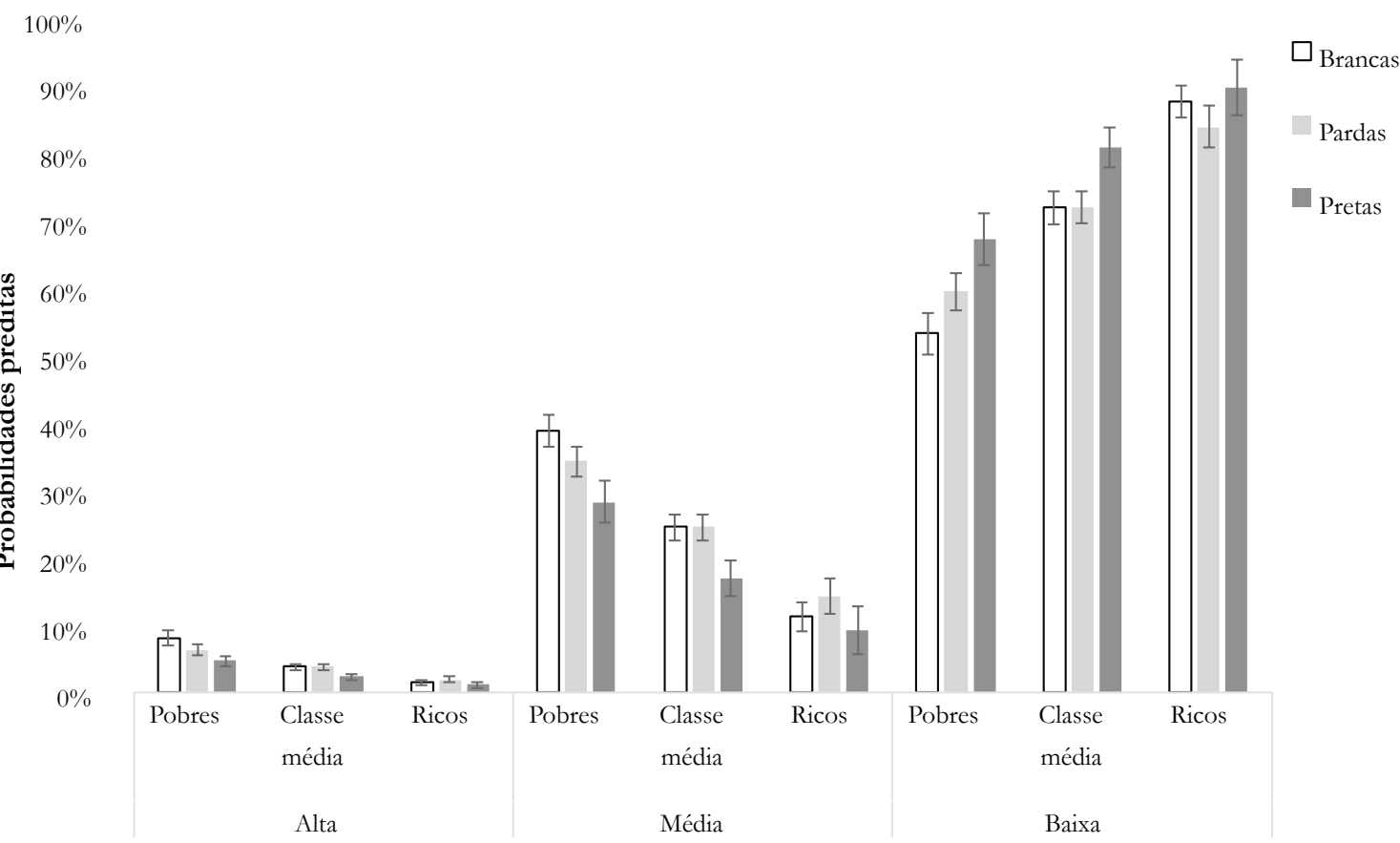

Concordância com frases racistas

Fonte: Elaboração própria, com base em Datafolha (2008). 
Figura 5

Probabilidades Preditas de Desejabilidade da Mistura Racial, por Raça e Classe Social

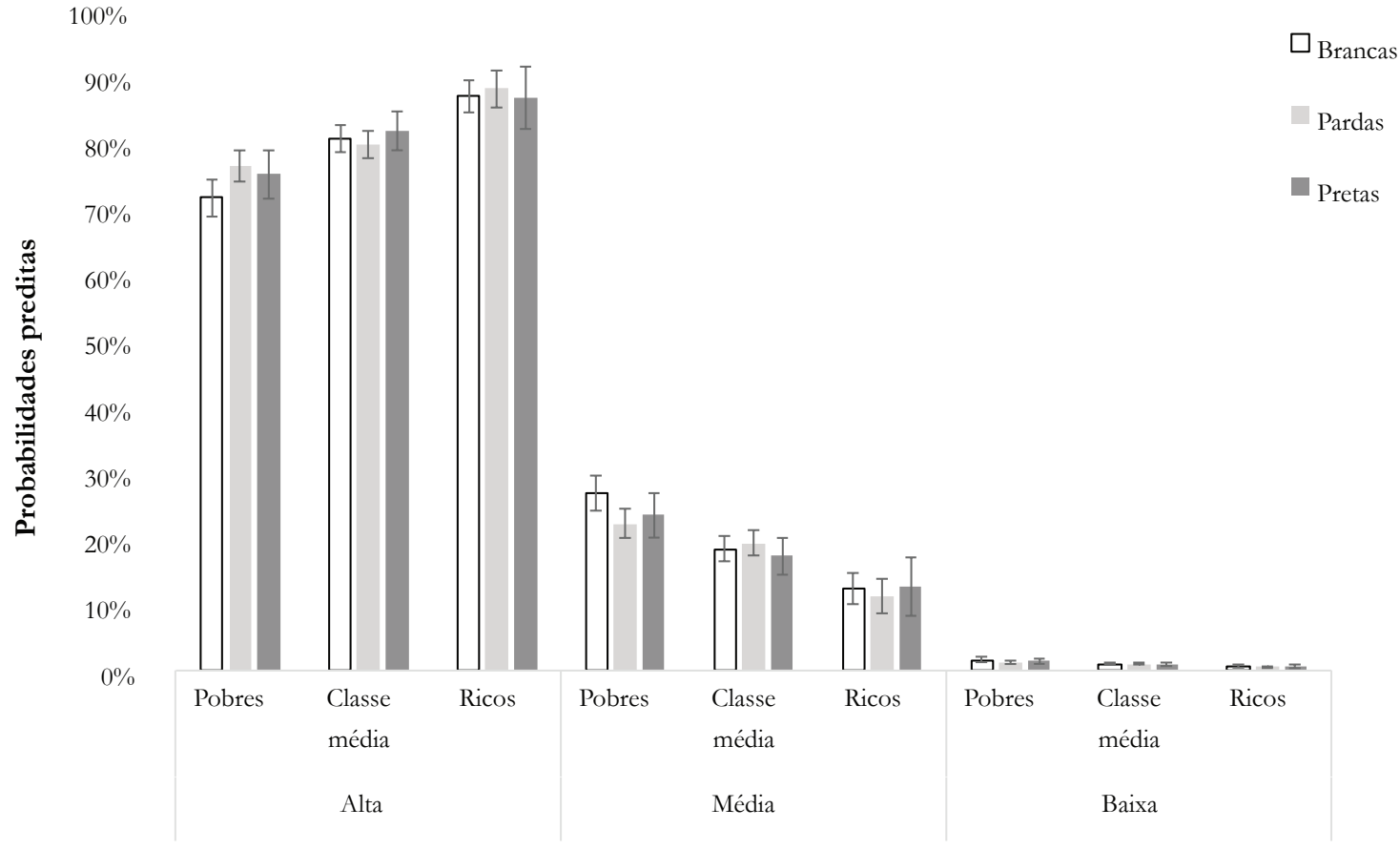

Desejabilidade da mistura racial

Fonte: Elaboração própria, com base em Datafolha (2008). 


\section{GROUPNESS RACIAL E FLUTUAÇÓES ATITUDINAIS DE PARDOS ENTRE FRONTEIRAS SIMBÓLICAS E SOCIAIS}

\section{Jerônimo Oliveira Muniz, Nathália Porto e Mario Fuks}

Palavras-chave: Fronteiras raciais; Pardos; Atitudes raciais; Identidades; Interesses.

Neste artigo, examinamos a permeabilidade das fronteiras simbólicas raciais a partir da identificação e análise de atitudes referentes: (1) ao preconceito; (2) à mistura racial e (3) ao apoio às políticas de cotas. Mais especificamente, exploramos a hipótese de que as opinióes posicionais dos pardos, em virtude da sua localização intermediária no espectro de cor brasileiro, são marcadas por uma flutuação entre os padrôes adotados por brancos e por pretos. Verificamos que há convergência atitudinal entre os grupos raciais, com exceção da discriminação racial, temática na qual brancos e pardos assumem padróes similares. Este resultado fortalece a visão dos indivíduos pardos como negociadores de fronteiras - seja ao se distanciar dos pretos, como no racismo, ou se aproximar deles, como no caso das cotas - em consonância com as identidades e interesses implicados em sua posição no continuum de cor.

\section{RACIAL GROUPNESS AND ATTITUDINAL FLUCTUATIONS OF PARDOS BETWEEN SOCIAL AND SYMBOLIC FRONTIERS}

\section{Jerônimo Oliveira Muniz, Nathália Porto and Mario Fuks}

Keywords: Racial boundaries; Pardos; Racial attitudes; Identities; Interests.

In this article, we examine the permeability of racial symbolic boundaries through the identification and analysis of attitudes concerning the following aspects: (1) prejudice; (2) racial mixing, and (3) support for racial quota policies. More specifically, we explore the hypothesis that the positional opinions of pardos, due to their intermediate location in the Brazilian color spectrum, are marked by a fluctuation between the patterns adopted by whites and by blacks. We found an attitudinal convergence between racial groups, with the exception of racial discrimination, in which whites and pardos assume similar patterns. This result suggests that brown individuals are boundary negotiators - whether to distance themselves from blacks, as in the case of racism, or to approach them, as in the case of quotas - in line with the identities and interests implied by their position on the color continuum.

\section{GROUPNESS RACIAL ET LES FLUCTUATIONS ATTITUDINALES DES METIS ENTRE LES FRONTIERES SYMBOLIQUES ET SOCIALES}

Jerônimo Oliveira Muniz, Nathália Porto et Mario Fuks

Mots-clés: Frontières raciales; Métis; Attitudes raciales; Identités; Intérêts.

Dans cet article, nous examinons la perméabilité des frontières symboliques raciales sur la base de l'identification et de l'analyse des attitudes concernant: (1) les préjugés; (2) le mélange racial et (3) le soutien aux politiques des quotas. Plus précisément, nous avons exploré l'hypothèse selon laquelle les points de vue des métis, en raison de leur situation intermédiaire dans le spectre de couleur brésilien, sont marqués par une fluctuation entre les normes adoptées par les blancs et les noirs. Nous avons vérifié qu'il existe une convergence d'attitudes entre les groupes raciaux, à l'exception de la discrimination raciale, un thème dans lequel les blancs et les métis assument des codes similaires. Ce résultat renforce l'idée des individus métis en tant que négociateurs frontaliers - soit en prenant du recul par rapport aux noirs, comme dans le racisme, soit en s'approchant d'eux, comme dans le cas des quotas - en consonance avec les identités et les intérêts impliqués selon leur position dans le continuum de couleur. 